\title{
LA RÉFORME DE LA FONCTION CONSULTATIVE EN WALLONIE
}

\section{Anne Guisset}

CRISP | « Courrier hebdomadaire du CRISP »

2017/39 $n^{\circ} 2364-2365$ | pages 5 à 66

ISSN 0008-9664

Article disponible en ligne à l'adresse :

https://www.cairn.info/revue-courrier-hebdomadaire-du-crisp-2017-39-page-5.htm

Distribution électronique Cairn.info pour CRISP.

(c) CRISP. Tous droits réservés pour tous pays.

La reproduction ou représentation de cet article, notamment par photocopie, n'est autorisée que dans les limites des conditions générales d'utilisation du site ou, le cas échéant, des conditions générales de la licence souscrite par votre établissement. Toute autre reproduction ou représentation, en tout ou partie, sous quelque forme et de quelque manière que ce soit, est interdite sauf accord préalable et écrit de l'éditeur, en dehors des cas prévus par la législation en vigueur en France. Il est précisé que son stockage dans une base de données est également interdit. 
Courrier hebdomadaire

$$
\mathrm{n}^{\circ} 2364-2365 \cdot 2017
$$

\title{
La réforme de la fonction consultative en Wallonie
}

\author{
Anne Guisset
}

(RiSP 


\section{Courrier hebdomadaire}

Rédacteur en chef : Cédric Istasse

Assistante éditoriale : Fanny Giltaire

Le Courrier hebdomadaire est soutenu par l'Administration générale de l'Enseignement et de la Recherche scientifique de la Fédération Wallonie-Bruxelles. Il est également publié avec l'aide financière du Fonds de la recherche scientifique-FNRS.

Une version numérique du Courrier hebdomadaire est disponible en pay per view (au numéro) et en accès gratuit pour les abonnés sur le site portail de CAIRN (http://www.cairn.info).

Le numéro simple : 6,90 euros - le numéro double : 12,40 euros

Abonnement : 235,00 euros

Souscription, commandes et informations :

CRISP - Place Quetelet, 1A - 1210 Bruxelles

Tél : 32 (0)2 2110180 - Fax : 32 (0)2 2197934

http://www.crisp.be - info@crisp.be

IBAN BE51 310027157662 - Swift BBRUBEBB

Éditeur responsable : Jean Faniel - Place Quetelet, 1A - 1210 Bruxelles

Tous droits de traduction, d'adaptation ou de reproduction par tous procédés, y compris la photographie et le microfilm, réservés pour tous pays.

ISSN 00089664 


\section{TABLE DES MATIÈRES}

INTRODUCTION

1. HISTORIQUE DE LA FONCTION CONSULTATIVE WALLONNE (1939-2014) 8

1.1. Le lobbying wallon auprès de l'État central 8

$\begin{array}{lr}\text { 1.2. Les phases d'institutionnalisation } & 10\end{array}$

1.2.1. La loi-cadre du 15 juillet $1970 \quad 10$

1.2.2. Le décret wallon du 25 mai $1983 \quad 12$

1.3. La multiplication des compétences régionales et la rationalisation de la fonction consultative $\quad 14$

1.3.1. L'accroissement des compétences de la Région wallonne au fil des réformes de l'État et des accords avec la Communauté française $\quad 15$

1.3.2. Les décrets wallons du 6 novembre 2008 portant rationalisation de la fonction consultative $\quad 16$

2. LA FONCTION CONSULTATIVE WALLONNE AVANT LA RÉFORME DE 201718

2.1. Préalable : le découpage institutionnel de la fonction consultative régionale et communautaire 18

2.1.1. Les Conseils économiques et sociaux régionaux (Wallonie, Bruxelles, Flandre) 18

2.1.2. Le Conseil économique et social de la Communauté française 20

2.1.3. Le Conseil économique et social de la Communauté germanophone 20

2.2. Le Conseil économique et social de Wallonie 21

2.2.1. Le champ d'intervention 21

2.2.2. Les structures : assemblée générale, bureau, commissions internes
et groupes de travail

2.2.3. Les conseils spécialisés 25

$\begin{array}{ll}\text { 2.3. Les autres types de consultation } & 28\end{array}$

3. LE PROCESSUS DE RÉFORME DE LA FONCTION CONSULTATIVE WALLONNE (2014-2017) 29

3.1. L'origine de la réforme $\quad 29$

3.1.1. Les appels des acteurs $\quad 30$

3.1.2. Le lancement de la réforme 31

3.2. Le processus décisionnel $\quad 32$

3.2.1. L'état des lieux et les premières propositions 32

Les propositions du Groupe des partenaires sociaux wallons (16 mars 2015) 32

L'inventaire des instances consultatives régionales 35

La note d'orientation du gouvernement wallon (23 juillet 2015) 35

3.2.2. Les débats autour des avant-projets de décret 36

La première lecture $\quad 37$

La deuxième lecture $\quad 38$

La troisième lecture $\quad 42$

3.2.3. Les débats autour des projets de décret 43

3.2.4. L'adoption des décrets 46 
3.3. Les suites de la réforme

3.3.1. L'architecture de la fonction consultative réformée

3.3.2. Les débuts de la mise en place de la réforme 


\section{INTRODUCTION}

En Belgique, la fonction consultative est un élément inhérent à la prise de décision politique. Elle rassemble diverses parties prenantes dont l'opinion et/ou l'expertise est transmise aux décideurs politiques sous la forme d'avis. Au cours des cinq dernières décennies, l'évolution des enjeux politiques ainsi que celle du paysage institutionnel belge ont profondément transformé cette fonction consultative. Au niveau régional wallon, la fonction consultative est en grande partie centralisée au sein du Conseil économique et social de Wallonie (CESW). Depuis les années 1970, cet organisme constitue la figure de proue de la fonction consultative wallonne.

La fonction consultative consiste en l'élaboration et la remise d'avis, provenant d'organisations de la société civile (au sens large, incluant les interlocuteurs sociaux ${ }^{1}$ ), à destination des autorités publiques. En Belgique, elle est en outre caractérisée par des arrangements de type néo-corporatiste ${ }^{2}$ et consociatif ${ }^{3}$, qui favorisent la participation des "représentants des différents groupes considérés comme importants dans une société " ${ }^{4}$. C'est pourquoi, dans la tradition belge de la concertation sociale, il est coutumier d'envisager la consultation comme une forme d'association des interlocuteurs sociaux à la décision politique dans les matières économiques et sociales ${ }^{5}$. À cet égard, les institutions à travers lesquelles prennent place les dispositifs consultatifs remplissent généralement d'autres fonctions associées à la concertation sociale et exercées par les interlocuteurs sociaux, telles que la négociation bipartite ou la concertation tripartite.

Ces fonctions de consultation, de négociation et de concertation se distinguent sur la base de leur déroulement, des effets qu'elles produisent et de leur rapport à l'autorité publique ${ }^{6}$. La consultation se déroule généralement sans la participation de l'autorité publique à la formulation des avis. Il s'agit, dans la mesure du possible, de dégager des

* Cette étude a été réalisée grâce à l'aide financière du FRS-FNRS (FRESH) et à l'appui documentaire du CESW.

Les interlocuteurs sociaux sont les « représentants syndicaux et patronaux mandatés pour défendre les intérêts de leurs organisations dans les organes officiels ou informels de la concertation sociale et dans leur rencontre avec les responsables politiques » (É. ARCQ, La concertation sociale, Dossier n 70 , Bruxelles, CRISP, 2008, p. 134). Pour plus de détails sur ces organisations, cf. J. FANIEL, "Caractéristiques et spécificités des syndicats belges » et É. ARCQ, "Les organisations patronales », in É. ARCQ, M. CAPRON, É. LÉONARD, P. REMAN (dir.), Dynamiques de la concertation sociale, Bruxelles, CRISP, 2010, p. 93-119 et 121-146.

2 Forgé en 1974 par le politologue Philippe C. Schmitter, le concept de néo-corporatisme décrit un système de représentation d'intérêts dans lequel coexistent un faible nombre d'organisations qui se partagent un monopole de la représentation attribué par l'État au regard de certaines caractéristiques et conditions (P. C. SCHMitTER, «Still the Century of Corporatism? », The Review of Politics, volume 36, ${ }^{\circ}$ 1, 1974, p. 85-131).

3 Développé à la fin des années 1960 par le politologue Arend Lijphart, le concept de consociationalisme décrit le mode de gouvernement de sociétés démocratiques fragmentées (par exemple, entre différents piliers idéologiques) qui cherchent à garantir leur stabilité en associant les élites de chaque sous-groupe de la société au sein des différentes institutions (A. LIJPHART, "Consociational Democracy ", World Politics, volume $\left.21, \mathrm{n}^{\circ} 2,1969, \mathrm{p} .207-225\right)$.

D. SINARDET, «Le fédéralisme consociatif belge, vecteur d'instabilité ? ", Pouvoirs, n 136, 2011, p. 22.

É. ARCQ, La concertation sociale, op. cit., p. 12.

Cf. Ibidem, p. 13-76. 
positions consensuelles entre les différentes parties prenantes. Ils sont transmis aux autorités publiques, qui ont la liberté relative de les suivre ou non. La négociation repose sur le rapport conflictuel qu'entretiennent les travailleurs et les employeurs et prend la forme de discussions formalisées entre les représentants de ceux-ci. Elle est encadrée juridiquement, en ce qui concerne tant son déroulement (dans les organes officiels de négociation) que la forme contraignante prise par ses résultats (par exemple, une convention collective). La concertation s'apparente à une forme de codécision impliquant les représentants des travailleurs et des employeurs ainsi que les pouvoirs publics; elle est donc tripartite. Ce sont les pouvoirs publics qui s'engagent à mettre en œuvre formellement les ententes issues de la concertation.

La consultation se distingue en outre de la négociation et de la concertation par le fait qu'elle n'est pas l'apanage des seuls interlocuteurs sociaux. En effet, bien qu'elle soit déjà ancienne dans le domaine socio-économique, la consultation s'est développée dans de multiples autres matières, par le biais d'un nombre important d'instances consultatives. Dans ces domaines-là, il arrive régulièrement que d'autres acteurs que les organisations syndicales et patronales prennent part à la consultation. C'est l'ensemble des instances consultatives ayant pour vocation de remettre des avis aux pouvoirs publics qui forme la fonction consultative ${ }^{7}$.

Le présent Courrier hebdomadaire est consacré à la fonction consultative wallonne, à son organisation par le CESW et à ses évolutions. En particulier, il étudie la dernière réforme en date dans ce domaine. Le 23 juillet 2014, le ministre-président wallon Paul Magnette (PS) a en effet présenté la déclaration de politique régionale de son gouvernement $(\mathrm{PS} / \mathrm{CDH})$, dans laquelle figurait un objectif de "rationalisation» de la fonction consultative ${ }^{8}$. S'est alors mis en marche un processus de réforme des décrets existants en la matière, piloté par le ministre-président lui-même. La réforme a été adoptée par le Parlement wallon le 15 février 2017 et est entrée en vigueur au début du mois de juillet suivant. Au cours des deux années et demie qu'a duré ce processus de réforme, les débats ont permis de mettre en lumière et parfois en tension les principes constitutifs de la fonction consultative wallonne. En effet, cette réforme a été loin de revêtir un caractère anecdotique, comme l'ont notamment montré les différentes questions de fond soulevées par les divers acteurs qui se sont mobilisés à l'occasion de ce processus. Au-delà d'une réorganisation conjoncturelle, cette réforme soulève en effet la question de la place et de la forme de la fonction consultative dans la démocratie représentative wallonne.

Le premier chapitre de ce Courrier hebdomadaire contextualise la fonction consultative wallonne en parcourant les principales étapes historiques ayant joué un rôle transformateur sur sa structure. Le deuxième chapitre présente le fonctionnement de la fonction consultative wallonne tel qu'il avait cours avant la réforme opérée en 2017. Le troisième et dernier chapitre étudie cette récente réforme. Celle-ci restant encore partiellement à mettre en œuvre à l'heure de publier ces lignes, l'analyse s'étendra principalement ici jusqu'à son adoption par le Parlement wallon, en février 2017. Cette analyse sera toutefois suivie par une présentation plus succincte des événements s'étant déroulés par la suite, jusqu'au $1^{\text {er }}$ mars 2018. Précisons par ailleurs que cette réforme «touche à l'ensemble

\footnotetext{
Ibidem, p. 43.

Gouvernement wallon, « Oser, innover, rassembler », Déclaration de politique régionale, 23 juillet 2014, p. 93.
} 
des compétences de la Wallonie et concerne donc un nombre très important de structures et d'interlocuteurs, dans des domaines variés " ${ }^{9}$. Dès lors, ce Courrier hebdomadaire mettra en évidence les transformations qui ont été les plus centrales et les éléments de débat qui ont été les plus saillants tout au long du processus de réforme, mais il ne prétendra pas lister de façon exhaustive l'ensemble des dispositions qui ont été concernées par cette réforme.

9 Parlement wallon, Commission des Affaires générales et des Relations internationales, Projets de décret modifiant le décret du 6 novembre 2008 portant rationalisation de la fonction consultative et diverses dispositions relatives à la fonction consultative [et] modifiant le décret-cadre du 6 novembre 2008 portant rationalisation de la fonction consultative pour les matières réglées en vertu de l'article 138 de la Constitution et diverses dispositions relatives à la fonction consultative. Rapport, $\mathrm{n}^{\circ} 601 / 14$ et 602/4, 16 janvier 2017, p. 6. 


\section{HISTORIQUE DE LA FONCTION CONSULTATIVE WALLONNE (1939-2014)}

Ce premier chapitre retrace l'historique de la fonction consultative wallonne. Cette histoire suit de près l'évolution de la structure institutionnelle de l'État belge. Son point de départ se situe à la fin des années 1930, avec l'apparition du Conseil économique wallon (CEW), destiné à défendre les intérêts et à promouvoir les atouts de la Wallonie en matière économique, auprès de l'État belge et face à la Flandre. Depuis sa création jusqu'à aujourd'hui, le Conseil a connu quatre changements d'appellation ainsi que plusieurs modifications structurelles, qui sont détaillées chronologiquement dans les trois sections de ce chapitre.

La première section revient sur les circonstances de création du CEW, sur la nature de ses activités et sur son fonctionnement jusqu'à la fin des années 1960. La deuxième section continue le récit pour les années 1970 et la première partie des années 1980. À cette époque, l'autonomisation effective du niveau régional, avec la mise sur pied d'organes exécutif, législatif et administratif, a conduit à l'institutionnalisation du Conseil en tant qu'organe paritaire (entre les organisations représentatives des employeurs et celles représentatives des travailleurs), interlocuteur officiel de l'exécutif wallon. La troisième section fait le point sur les effets du développement de la fonction consultative wallonne, et plus particulièrement sur les effets ayant conduit à « rationaliser » celle-ci dans la première décennie du XXI ${ }^{\mathrm{e}}$ siècle ${ }^{10}$. Les accroissements successifs de compétences de la Wallonie ont conduit la fonction consultative wallonne à se démultiplier pour couvrir une variété et un nombre de matières croissants. Ce phénomène a provoqué diverses initiatives visant à réformer la fonction consultative wallonne afin de procéder à sa simplification.

\subsection{LE LOBBYING WALLON AUPRÈS DE L'ÉTAT CENTRAL}

Le Conseil économique wallon (CEW) puise ses racines dans le Mouvement wallon « au sens large du mot ${ }^{11}$. À travers lui, il s'agit d'examiner les problématiques économiques

10 Selon l'expression utilisée dans le titre des décrets wallons adoptés en 2008 et modifiés en 2017 (cf. infra), à savoir « décrets portant rationalisation de la fonction consultative ".

M.-P. Herremans, «Conseil économique wallon CEW », Courrier hebdomadaire, CRISP, n 144, 1962, p. 2. Cf. aussi «Défense et représentation des intérêts économiques wallons : le Conseil économique wallon », Courrier hebdomadaire, CRISP, n 34, 1959. 
de l'époque (telles que le développement des voies navigables, ferroviaires et routières, ou l'attractivité industrielle de la région) à la lumière des intérêts wallons. La concentration des forces vives wallonnes dans un lieu dédié à la réflexion sur les grands chantiers économiques à venir est une entreprise que plusieurs personnalités wallonnes de l'époque appellent alors de leurs voux ${ }^{12}$. Celles-ci ont par ailleurs sous les yeux l'exemple du Vlaams Economisch Verbond (VEV), une organisation patronale de défense des intérêts économiques flamands ${ }^{13}$.

L'impulsion pour la création du CEW vient en 1938 de la Ligue d'action wallonne de Liège ${ }^{14}$, qui a identifié le besoin de développer une doctrine économique pour la Wallonie ${ }^{15}$. Cependant, à la différence de celle du VEV flamand - qui est un groupe strictement patronal (à l'image du Comité central industriel - CCI, ancêtre de l'actuelle Fédération des entreprises de Belgique - FEB, au niveau national) -, la composition du CEW est dès le départ mixte, rassemblant une centaine de personnalités issues des milieux industriel, syndical, politique, agricole et scientifique qui s'expriment en leur nom propre ${ }^{16}$.

La constitution du CEW est officiellement annoncée le 9 juillet 1939. Cependant, la publication des statuts de l'asbl au Moniteur belge doit être postposée à une date indéterminée, en raison du déclenchement de la Seconde Guerre mondiale. Le CEW fonctionne alors dans la clandestinité jusqu'à la libération, et ses statuts sont finalement publiés au Moniteur belge le 21 juillet 1945. Y sont précisés les objectifs de l'organisation. Celle-ci « a pour but essentiel la défense et le développement des régions wallonnes au point de vue économique : elle aura pour tâche d'empêcher l'émigration de l'industrie wallonne, de soutenir les industries existantes, de susciter et d'encourager la création d'industries nouvelles en Wallonie, de veiller à la sauvegarde des intérêts wallons lors de la conclusion d'accords internationaux, de se préoccuper de toutes les questions économiques, financières, sociales, scientifiques, pédagogiques et artistiques intéressant le développement économique de la Wallonie ${ }^{17}$.

Dans ce cadre, les activités du CEW consistent à examiner les problématiques précitées, à formuler des positions et à les relayer " par tous les moyens opportuns et notamment par la voie de la presse, par des publications, par des conférences, par des interventions, cette énumération étant exemplative et non limitative » (article 2 des statuts). Le CEW constitue en ce sens un véritable groupe de pression militant pour les intérêts wallons. Il utilise l'influence des personnalités qui le composent pour asseoir la crédibilité de ses travaux et pour influencer les autorités de l'État central et l'opinion publique ${ }^{18}$.

2 Institut Jules-Destrée, «Conseil économique wallon (1938-1971) », www.wallonie-en-ligne.net.

D. LUYTEN, "L'économie et le mouvement flamand ", Courrier hebdomadaire, CRISP, n² 2076, 2010, p. $23,29,33$ et 35 .

Institut Jules-Destrée, «Ligue d'action wallonne de Liège (1923)», www.wallonie-en-ligne.net.

Institut Jules-Destrée, «Conseil économique wallon (1938-1971)», op. cit.

O. Ongena, "Geschiedenis van het regionaal overleg », in C. Devos, M. Mus, P. Humblet (dir.), De toekomst van het sociaal overleg, Gand, Academia Press, 2011, p. 15.

17 Statuts du CEW, 21 juillet 1945 (cité par «Défense et représentation des intérêts économiques wallons : le Conseil économique wallon », op. cit., p. 7).

18 Ibidem, p. 9. 
Les différentes composantes territoriales de la Wallonie y sont représentées, en suivant une répartition des sièges entre les provinces ${ }^{19}$ et les grandes villes ${ }^{20}$. La présidence tournante est assurée par les gouverneurs de province wallonne dès $1948^{21}$. En outre, le CEW est structuré non seulement en commissions thématiques au niveau central mais également en sections régionales ${ }^{22}$. À cette époque, le siège de l'organisation est situé à Liège.

\subsection{LES PHASES D'INSTITUTIONNALISATION}

Le statut de groupe de pression du CEW est amené à se modifier lorsqu'émergent, dans le courant des années 1960, dans un contexte de négociations autour des futures formes de l'État belge, des revendications visant à institutionnaliser les conseils économiques régionaux ${ }^{23}$. Cette étape est franchie quelques mois avant la réforme constitutionnelle du 24 décembre 1970.

Bien que préfigurant les dynamiques de la concertation wallonne, le CEW joue jusqu'alors un rôle informel dans la prise de décision politique, puisqu'il n'a aucun statut public et que ses membres (qui sont répartis à cette époque selon une base tripartite incluant les interlocuteurs sociaux et des représentants politiques) s'expriment en leur nom propre. La loi-cadre du 15 juillet 1970 portant organisation de la planification et de la décentralisation économique fait sortir le CEW de cette position de groupe de pression en l'institutionnalisant et en le reconnaissant comme l'interlocuteur wallon du pouvoir central. La seconde phase d'institutionnalisation a lieu une décennie plus tard, lorsque les lois institutionnelles des 8 et 9 août 1980 permettent la mise sur pied effective d'un exécutif et d'une assemblée parlementaire au niveau régional wallon. Les membres du CEW peuvent désormais investir les instances politiques régionales. Le CEW devient alors un organe bipartite de représentation des forces économiques et sociales de la Wallonie par le biais des interlocuteurs sociaux.

\subsubsection{La loi-cadre du 15 juillet 1970}

Dans les années 1960, les projets de loi portant sur les matières linguistiques et culturelles, d'une part, et sur la décentralisation économique, d'autre part, correspondent grosso modo respectivement aux aspirations flamande et wallonne à obtenir plus d'autonomie. Côté

19 À cette époque, le CEW recouvre les provinces wallonnes de Hainaut, de Liège, de Luxembourg et de Namur, ainsi que l'arrondissement de Nivelles dans la province de Brabant (cette dernière partie correspondant à l'actuelle province de Brabant wallon). Quant à elle, la "partie flamande du Brabant » (c'est-à-dire les arrondissements de Hal-Vilvorde et Louvain) fait partie de l'Economische Raad voor Vlaanderen (ERV). À ce sujet, cf. « Les Conseils économiques régionaux (CER) (I) », Courrier hebdomadaire, CRISP, $n^{\circ} 584,1972$, p. 3.

20 Par exemple, pour l'année 1961, cf. M.-P. Herremans, «Conseil économique wallon CEW », op. cit., p. 15-20.

"Les Conseils économiques régionaux (CER) (I)», op. cit., p. 9.

"Défense et représentation des intérêts économiques wallons : le Conseil économique wallon », op. cit., p. 4 et 20.

Institut Jules-Destrée, « Conseil économique wallon (1938-1971)», op. cit. 
wallon, il s'agit notamment d'encourager l'instauration d'institutions qui favoriseront le développement économique de la région. C'est dans cette perspective qu'est adoptée la loi-cadre du 15 juillet 1970 portant organisation de la planification et de la décentralisation économique ${ }^{24}$ - dite loi Terwagne, du nom du ministre des Relations communautaires du gouvernement Eyskens IV (CVP/PS/SP/PSC), le socialiste wallon Freddy Terwagne. Cette loi organise la planification, dans le but - précisé en son article $1-$ de parvenir à une expansion économique maximale et équilibrée. Pour ce faire, sont mis en place un plan économique quinquennal et des organismes dont les fonctions sont destinées à coordonner les différents aspects de la planification. C'est également par cette loi que sont établis, au niveau national, le Bureau du plan (actuel Bureau fédéral du plan - BFP) et, au niveau régional, les sociétés de développement régional et les conseils économiques régionaux (chapitre II de la loi).

Aux côtés du Gewestelijke Economische Raad voor Vlaanderen (GERV, Conseil économique régional pour la Flandre) et du Conseil économique régional pour le Brabant (CERB) ${ }^{25}$, également visés par cette loi, le CEW devient un interlocuteur institutionnalisé du pouvoir central. Il prend le statut de partie prenante formellement reconnue dans le développement économique de la Wallonie. L'asbl de droit privé se dissout alors pour faire place au Conseil économique régional pour la Wallonie (CERW), doté de la personnalité civile ${ }^{26}$. Le CERW est institué le 16 octobre 1971 à Namur, dans un bâtiment appartenant au gouvernement provincial namurois ${ }^{27}$. Ses compétences ont une portée consultative; elles se déclinent en compétences d'avis et de recommandation, essentiellement envers le gouvernement national, sur les différentes mesures liées à la planification économique visée par la loi-cadre du 15 juillet $1970{ }^{28}$.

Le CERW est un organe tripartite dont la composition est réglée (de même que celle de son pendant flamand, le GERV) par le premier paragraphe de l'article 11 de la loi Terwagne. Celui-ci indique que 60 membres sont nommés par le Roi - c'est-à-dire par le gouvernement national - pour une durée de quatre ans. Une première moitié des membres rassemble les interlocuteurs sociaux, sur une base paritaire : 15 membres des organisations représentatives de l'industrie, des grandes entreprises non industrialisées, des classes moyennes et de l'agriculture, d'une part, et 15 membres des organisations

La partie wallonne de la province de Brabant est alors couverte à la fois par le CEW et par le CERB, tandis que la partie flamande de cette province l'est à la fois par le GERV et le CERB. Cf. "Les Conseils économiques régionaux (CER) (I) », op. cit., p. 4.

Article 9 de la loi-cadre du 15 juillet 1970.

«Les Conseils économiques régionaux (CER) (II) », Courrier hebdomadaire, CRISP, n 587, 1973, p. 6.

Le chapitre 1 de la loi-cadre du 15 juillet 1970 définit le rôle des conseils économiques et sociaux - aux côtés du Bureau du plan, du Conseil central de l'économie (CCE), du Conseil national du travail (CNT) et du Comité national d'expansion économique (CNEE) - dans la consultation préalable à l'adoption de plans économiques quinquennaux dans le cadre de la planification économique. À ce sujet, cf. en particulier l'article $7, \S 1^{\text {er }}$ : «Les directions générale et sectorielle du Bureau du plan dressent un inventaire des principaux choix techniquement possibles. Ceux-ci sont confrontés avec les options régionales par la direction régionale du Plan en collaboration avec les conseils économiques régionaux. Le Bureau du plan adresse ensuite les propositions. Les avis du Conseil [central] de l'économie, du Conseil national du travail, du Comité national d'expansion économique et des conseils économiques régionaux y sont annexés. Les Chambres se prononcent sur les options à prendre en considération. Après consultation des conseils économiques régionaux et du Comité national d'expansion économique, le projet de loi portant approbation finale du plan élaboré est déposé pour le $1^{\text {er }}$ novembre de l'année précédant sa mise en application. Les conclusions des organes (...) sont jointes au projet de loi. La même procédure est suivie pour les adaptations annuelles à l'occasion de la discussion du budget économique ». 
représentatives de travailleurs, d'autre part. Une seconde moitié regroupe des représentants politiques : 18 parlementaires et 12 mandataires provinciaux ${ }^{29}$, représentés proportionnellement à la force électorale des partis. En outre, 6 à 10 experts en matières économiques sont cooptés. Les membres du CERW sont nommés pour un mandat de 5 ans ${ }^{30}$.

Cette composition et les nominations qui en découlent ont été élaborées de concert avec les membres de l'ancien CEW. En comparaison avec le fonctionnement de ce dernier, on note que la présidence passe des gouverneurs de province à des représentants des interlocuteurs sociaux (suite à un "coup de force» de ces derniers) ${ }^{31}$. Les différents membres du CERW se répartissent le travail en formant des commissions de 8 membres; le nombre et les thématiques de ces commissions s'ajustent suivant les besoins.

Par ses fonctions, sa composition et surtout son institutionnalisation, le CERW formalise les rapports entre le monde politique et le monde socio-économique. Il dispose également, en l'absence d'organes régionaux élus, d'une grande représentativité ${ }^{32}$. Celle-ci perdurera lorsque la Région wallonne sera, dix ans plus tard, dotée d'organes législatif, exécutif et administratif.

\subsubsection{Le décret wallon du 25 mai 1983}

Les organes politiques régionaux se mettent en place suite aux réformes institutionnelles des 8 et 9 août 1980 (qui appliquent l'article 107quater de la Constitution issu de la réforme constitutionnelle du 24 décembre 1970) ${ }^{33}$. Pendant cette période d'installation, le CERW poursuit ses activités, tout en sachant qu'il ne tardera pas à connaître une transformation interne. En effet, la réforme du CERW fait partie des priorités tant du Conseil régional wallon (installé le $1^{\text {er }}$ octobre 1980) que de l'exécutif wallon (de composition PS/PRL/PSC) ${ }^{34}$.

Dès le mois de mai 1982, cinq conseillers régionaux wallons du PSC (André Tilquin, Albert Gehlen, Albert Liénard, Guy Lutgen et Émile Wauthy) et un du PRL (Serge Kubla) déposent une proposition de décret visant à adapter la composition et les missions du CERW à la situation nouvelle issue de la récente réforme de l'État ${ }^{35}$. Quatre séances suffisent à la Commission de la Politique économique, de l'Énergie et de l'Emploi pour

29 La loi exige que le choix des parlementaires désignés pour siéger dans chacun des trois conseils économiques régionaux rencontre de manière " appréciée » l'aire géographique de chacun de ceux-ci. Quant aux mandataires provinciaux, ils doivent provenir des conseils provinciaux (ou des sections de conseil provincial intéressées, pour la province de Brabant) des provinces (ou des arrondissements, pour la province de Brabant) relevant de la couverture territoriale de chaque conseil économique régional. Cf. « Les Conseils économiques régionaux (CER) (I) », op. cit., p. 11-12.

30 Après son installation le 16 octobre 1971, le CERW voit sa composition renouvelée le 15 décembre 1975 et le 24 mars 1980 (ces dates correspondant aux séances officielles d'installation du CERW nouvellement composé).

«Les Conseils économiques régionaux (CER) (I) », op. cit., p. 9.

«Les Conseils économiques régionaux (CER) (II)», op. cit., p. 19.

Loi spéciale du 8 août 1980 de réformes institutionnelles, Moniteur belge, 15 août 1980 ; Loi ordinaire du 9 août 1980 de réformes institutionnelles, Moniteur belge, 15 août 1980.

34 Renseignements fournis par l'Institut Jules-Destrée.

35 Conseil régional wallon, Proposition de décret modifiant, en ce qui regarde le Conseil économique régional pour la Wallonie, la loi-cadre du 15 juillet 1970 portant organisation de la planification et de la décentralisation économique, et instaurant un Conseil économique et social de la Région wallonne, n 23/1, 4 mai 1982. 
obtenir un consensus sur ce dossier. Lors de sa séance plénière du 18 mai 1983, le Conseil régional wallon adopte le décret à l'unanimité. Entre autres, ce texte change la dénomination du CERW en Conseil économique et social de la Région wallonne (CESRW) et modifie la composition de cette instance : désormais, seuls les interlocuteurs sociaux en sont membres.

L'explication de cette modification de composition figure notamment dans cette intervention du conseiller régional wallon Guy Pierard (PRL) : « La principale raison est apparue avec l'installation de notre assemblée régionale. En effet, il s'est rapidement posé un problème que je ne qualifierai pas nécessairement d'incompatibilité, mais plutôt de dualité dans le chef des parlementaires élus directs siégeant au sein du [Conseil régional wallon] et de certains de ces parlementaires représentant leur famille politique au CERW. En effet, le [CERW] est souvent amené à émettre un avis sur un projet, voire sur une proposition de décret, et (...) il est aberrant pour un parlementaire siégeant au [CERW] de se donner un avis à lui-même puisque, en fin de compte, c'est au sein de la commission ad hoc [du Conseil régional wallon] que le projet ou la proposition viendra à l'examen. De plus, lorsqu'un parlementaire engage son parti au CERW sur un projet ou une proposition de décret, il engage dans une certaine mesure ses collègues siégeant au [Conseil régional wallon]. Ce n'est pas sérieux et il était grand temps de modifier la composition du CERW ${ }^{36}$. Willy Thys, ancien membre du CERW, résumera plus tard en ces termes la portée de ce changement sur la nature du Conseil : « Jusque-là, nous étions dans un combat global et militant. Par la suite, nous nous sommes mis dans une logique de rencontre patrons-syndicats ${ }^{37}$.

Daté du 25 mai suivant, le décret ne parait pas au Moniteur belge avant le 20 mars $1984^{38}$. Pour sa part, l'installation du CESRW s'effectue le 2 avril 1984. Dans l'intervalle, le CERW a continué à fonctionner avec l'ensemble de ses membres, mandataires politiques et interlocuteurs sociaux. L'intervention de G. Pierard qui vient d'être reproduite permet à cet égard de saisir quelque peu la manière dont le CERW a concrètement fonctionné durant ce laps de temps.

Le décret wallon du 25 mai 1983 - toujours en vigueur aujourd'hui - modifie la loicadre du 15 juillet 1970 en ce qui concerne les modalités relatives à l'organe consultatif wallon et expose la nouvelle mouture de celui-ci. Le décret assigne trois missions au CESRW. Primo, remettre des avis (d'initiative ou sur demande) sur les matières touchant au développement économique de la région. Secundo, organiser la concertation entre les interlocuteurs sociaux et l'exécutif régional wallon (de manière à pouvoir délibérer au sujet des défis socio-économiques de la région). Tertio, assurer le secrétariat des autres commissions consultatives chargées de rendre des avis sur les matières gérées par la Région wallonne. Le Conseil adresse désormais ses recommandations et avis à destination, non plus du gouvernement national, mais de l'exécutif régional wallon nouvellement créé. C’est également cet exécutif régional qui nomme désormais les membres du CESRW.

Conseil régional wallon, Compte rendu intégral, $\mathrm{n}^{\circ} 11,18$ mai 1983, p. 6.

"Regards croisés : les “anciens" racontent... ", Revue Wallonie, CESW, n 100, 2009-2010, p. 12.

Décret wallon du 25 mai 1983 modifiant, en ce qui regarde le Conseil économique régional pour la Wallonie, la loi-cadre du 15 juillet 1970 portant organisation de la planification et de la décentralisation économique et instaurant un Conseil économique et social de la Région wallonne, Moniteur belge, 20 mars 1984 
Cette deuxième phase d'institutionnalisation, couplée à un changement de structure et de fonction, met quelques années à s'installer, dans un contexte institutionnel régional lui-même balbutiant. Le CESRW est finalement institué en $1988^{39}$. Son installation incrémentale ne l'empêche pas de jouer un rôle primordial dans la détermination des compétences régionales. Jean-Pierre Champagne, ancien président du CESRW, témoigne du rôle du Conseil pendant la décennie charnière 1980-1990 : " Il ne faut certainement pas mésestimer le rôle qu'a eu le Conseil pour la définition des compétences à régionaliser $»^{40}$.

Toujours dans le contexte de la mise en place des institutions régionales et de leurs activités, le décret du 25 mai 1983 est une première fois modifié par un décret du 7 mai 1991. Celui-ci stipule que le siège du CESRW et de ses commissions internes est désormais établi à Liège. Le transfert effectif de Namur vers Liège a lieu en 1994, lorsque le CESRW s'installe au Vertbois. Ce déménagement est à replacer dans le cadre des discussions autour de la répartition géographique des institutions régionales établie dans les années 1980. Selon la logique de ce plan d'affectation, les institutions à vocation économique étaient amenées à s'établir à Liège ${ }^{41}$.

Par la suite, le décret du 25 mai 1983 sera modifié à deux autres reprises (cf. infra). D'une part, par un décret du 30 avril 2009 relativement à la composition du Conseil. D'autre part, par un décret du 27 octobre 2011 consacrant un nouveau changement d'appellation, par lequel le CESRW s'appellera désormais le Conseil économique et social de Wallonie (CESW), la Région wallonne ayant elle-même décidé de privilégier l'appellation usuelle « Wallonie » pour se désigner.

\subsection{LA MULTIPLICATION DES COMPÉTENCES RÉGIONALES ET LA RATIONALISATION DE LA FONCTION CONSULTATIVE}

Le décret du 25 mai 1983 rend le CESRW compétent pour remettre des avis sur toutes les compétences de la Région wallonne. Il résulte de cette disposition que la fonction consultative wallonne a vocation à s'étendre au gré des compétences qui basculent dans la coupe régionale. Deux phénomènes peuvent contribuer à faire augmenter en nombre et en nature les domaines pour lesquels le pouvoir régional wallon, et donc le CESRW, est compétent: d'une part, les transferts de compétences de l'État central puis de l'Autorité fédérale vers les Régions et, d'autre part, les transferts de l'exercice de compétences de la Communauté française ${ }^{42}$ vers la Région wallonne en région de langue française.

Ces transferts, auxquels s'ajoutent les besoins des différents ministres wallons de collaborer avec le terrain ainsi que le contexte démocratique en crise entraînant une demande

\footnotetext{
É. ARCQ, La concertation sociale, op. cit., p. 63.

« Regards croisés : les “anciens" racontent... », op. cit., p. 12.

«Le Vertbois, siège du Conseil économique et social de Wallonie », http://connaitrelawallonie.wallonie.be.

Précisons que la Communauté française a décidé, en mai 2011, d'adopter la dénomination de «Fédération Wallonie-Bruxelles » dans sa communication interne et externe. Ce nouveau nom n'ayant cependant pas la portée juridique que lui donnerait une révision de la Constitution allant dans le même sens, nous maintiendrons, dans ce Courrier hebdomadaire, l'appellation constitutionnelle de Communauté française.
} 
croissante de l'opinion publique en faveur de plus de participation, conduisent à multiplier les instances consultatives de toutes sortes (conseils, commissions, comités, etc.). C'est dans ce cadre qu'apparaît la nécessité d'une première réforme de la fonction consultative wallonne, qui est opérée en 2008.

\subsubsection{L'accroissement des compétences de la Région wallonne au fil des réformes de l'État et des accords avec la Communauté française}

Au fil des réformes de l'État successives, la Région wallonne voit un nombre croissant de compétences auparavant nationales ou fédérales tomber dans son escarcelle. En général, les différentes instances consultatives (telles que les commissions d'agrément afférentes aux dispositifs fédéraux transférés) sont dirigées vers l'administration wallonne, à savoir vers l'actuel Service public de Wallonie (SPW) ${ }^{43}$ ou vers l'Office wallon de la formation professionnelle et de l'emploi (FOREM). Pour leur part, certaines missions du Conseil national du travail (CNT) sont transférées au CESW (sans que cela ne nécessite une réorganisation de celui-ci), par exemple celles ayant trait à la remise d'avis sur les ajustements budgétaires relatifs aux formations professionnelles. Notamment, la sixième réforme de l'État (2012-2014) procède au transfert de certaines matières d'emploi touchant historiquement à la concertation sociale. De ce fait, elle entraîne un renforcement de la concertation sociale régionale, via le CESW mais également par la création d'une nouvelle instance informelle : le Groupe des partenaires sociaux wallons (GPSW, cf. infra).

Outre par les différentes réformes de l'État, le volume des matières gérées par la Région wallonne s'accroît en vertu de deux accords passés avec la Communauté française.

Le 31 octobre 1992 est conclu l'accord intra-francophone dit de la Saint-Quentin. Dans le but d'alléger les finances de la Communauté française, l'accord permet le transfert de l'exercice de certaines compétences depuis celle-ci vers la Région wallonne, en région de langue française - et vers la Commission communautaire française (COCOF), en région bilingue de Bruxelles-Capitale -, sans transférer la totalité des budgets qui leur sont liés (le solde restant à la disposition de la Communauté française pour mener sa politique dans les compétences dont elle continue à assurer l'exercice). L'accord est mis en œuvre après une révision de la Constitution destinée à permettre ce type de transfert (via l'adoption d'un article 59quinquies, $\$ 1^{\text {er }}-$ actuel article 138 -, de la Constitution, le 5 mai 1993) dans le cadre de la quatrième réforme de l'État (réforme qui entérine par ailleurs la structure fédérale de l'État belge). Les matières concernées ressortissent de plusieurs domaines tels que la politique de santé, l'accueil et l'intégration des immigrés, le tourisme, etc.

43 Le SPW a vu le jour le 15 décembre 2008 et a été opérationnel à partir 12 février 2009. Né de la volonté de créer un ministère wallon unique, il résulte de la fusion du Ministère de la Région wallonne (MRW, institué au début des années 1980 pour accueillir les agents d'administration et les compétences transférés à la Wallonie) et du Ministère wallon de l'Équipement et des Transports (MET, mis sur pied en 1989, suite aux nouvelles réformes institutionnelles). Cf. M. PETIT JEAN, « Le régime des mandats dans l'administration wallonne », Courrier hebdomadaire, CRISP, n² 2166-2167, 2013, p. 25-32. 
Dans le cadre de la sixième réforme de l'État, et suite à l'accord intra-francophone dit de la Sainte-Émilie du 19 septembre 2013, la Communauté française procède à nouveau au transfert de l'exercice de certaines de ses compétences à la Région wallonne - et à la COCOF. Il s'agit cette fois de matières touchant à l'aide sociale, à la santé et aux allocations familiales.

\subsubsection{Les décrets wallons du 6 novembre 2008 portant rationalisation de la fonction consultative}

Suite à l'accord de la Saint-Quentin, le CESRW rédige une motion sur la fonction consultative qu'il publie le 11 avril $1994^{44}$. Déjà à cette époque, le CESRW en appelle à un regroupement des multiples structures consultatives résultant de l'accroissement des compétences de la Région wallonne, tout en affirmant son propre rôle central dans cette fonction (et, par conséquent, celui des interlocuteurs sociaux) et en soulignant la nécessité de faire appel à des experts extérieurs (sous l'égide et la coordination du CESRW).

Eu égard à l'accroissement régulier des compétences régionales, la fonction consultative wallonne est amenée à se densifier et à croître de façon parfois rapide mais pas toujours harmonieuse. Le besoin d'une "rationalisation » de la fonction consultative wallonne apparait de manière récurrente. Ainsi, il est exprimé par le CESRW dans un mémorandum rédigé à l'occasion des élections régionales du 13 juin 2004 : «Depuis quelques années, [la] volonté légitime et partagée de consultations a conduit, d'une part, à la multiplication de conseils, de commissions, de comités et, d'autre part, à l'émergence de nouveaux acteurs à côté des organisations de travailleurs et d'employeurs. Il est temps de rationaliser la fonction consultative pour en renforcer son influence et pour préserver l'efficacité et la crédibilité de tous les interlocuteurs concernés. C'est pourquoi le CESRW entend conduire avec le futur gouvernement wallon une réflexion en vue de moderniser, rationaliser et dynamiser la fonction consultative ».

Cet appel à la rationalisation de la fonction consultative fait l'objet d'une déclaration commune entre le gouvernement wallon Van Cauwenberghe I (PS/Fédération PRL FDF MCC/Écolo) et les interlocuteurs sociaux en juin 2004. Les objectifs sont repris dans la déclaration de politique régionale du gouvernement Van Cauwenberghe II (PS/CDH) en juillet 2004. L'année suivante, un processus de réflexion est lancé sous la houlette de la ministre de la Santé, de l'Action sociale et de l'Égalité des chances du gouvernement Di Rupo II (PS/CDH), Christiane Vienne (PS), puis, à partir de juillet 2007, de son successeur à ce poste dans le gouvernement Demotte I (PS/CDH) ${ }^{45}$, Paul Magnette (PS). La réforme est menée à son terme par Didier Donfut (PS), qui remplace P. Magnette à partir du 8 janvier 2008 (suite à la démission de ce dernier, le 21 décembre 2007).

Les objectifs poursuivis par cette réforme sont «d'optimiser et d'harmoniser le fonctionnement des organes ainsi que de réduire leur nombre avec pour but un

44 CESRW, « Motion A. 444 sur la fonction consultative wallonne », 11 avril 1994.

Les gouvernements wallons Van Cauwenberghe II, Di Rupo II et Demotte I se sont tous trois succédé durant la législature régionale 2004-2009. 
raccourcissement des délais de procédure ${ }^{46}$. La méthodologie suivie par le gouvernement wallon dans le dossier de cette réforme consiste en la mise en place d'une concertation avec le CESRW (ainsi qu'avec d'autres acteurs et instances concernés), en parallèle avec une sollicitation des différents ministres fonctionnels. Ces derniers sont chargés d'élaborer des propositions de réorganisation sur les instances consultatives relevant de leurs compétences, accompagnées de propositions de modifications décrétales (chaque instance étant réglementée par des dispositifs législatifs distincts, une modification transversale entraîne inévitablement la modification de plusieurs décrets).

Cette réforme aboutit à deux décrets datés du 6 novembre $2008{ }^{47}$ et destinés à harmoniser le fonctionnement de différentes instances consultatives wallonnes. La coexistence de deux décrets s'explique par la division entre les matières régionales à part entière, d'une part, et les matières dont l'exercice a été transféré de la Communauté française, d'autre part.

Avec les deux décrets du 6 novembre 2008, le nombre d'instances (conseils et commissions d'avis) passe de 75 à 53. Dans un objectif de réorganisation, le secrétariat de certaines commissions, jusqu'alors assuré par l'administration, est confié au CESRW ${ }^{48}$. La procédure de remise d'avis est désormais limitée à 35 jours ( 10 jours pour les procédures d'urgence). La rationalisation introduit des règles de fonctionnement transversales et communes aux instances consultatives, «telles que la systématisation de la présence de suppléants, la présence de représentants du gouvernement avec simple voix consultative, l'harmonisation de la durée des mandats à cinq ans avec renouvellement intégral, les sanctions en cas d'absences répétées ${ }^{49}$.

La mise en place d'une réforme aussi transversale s'avère lente et complexe. Le ministreprésident Rudy Demotte (PS) est encore interpellé à ce sujet au Parlement wallon en 2011. Les années qui suivent cette première réforme montrent que la rationalisation mise en place ne permet pas nécessairement de canaliser la démultiplication du nombre d'instances consultatives. La perspective d'un nouvel accroissement, dû à la sixième réforme de l'État, encouragera la reprise du dossier par le ministre-président P. Magnette, à l'arrivée au pouvoir de son gouvernement (PS/CDH) en juillet 2014 (cf. infra).

46 Parlement wallon, Projet de décret modifiant le décret du 6 novembre 2008 portant rationalisation de la fonction consultative et diverses dispositions relatives à la fonction consultative, $\mathrm{n}^{\circ} 601 / 1,4$ octobre $2016, \mathrm{p} .3$.

Décret wallon du 6 novembre 2008 portant rationalisation de la fonction consultative, Moniteur belge, 18 décembre 2008 ; Décret-cadre wallon du 6 novembre 2008 portant rationalisation de la fonction consultative pour les matières réglées en vertu de l'article 138 de la Constitution, Moniteur belge, 19 décembre 2008.

48 C'est le cas des commissions suivantes: Entreprises de formation par le travail/Organismes d'insertion socio-professionnelle (EFT/OISP), Organismes de formation relevant du Plan mobilisateur des technologies de l'information et de la communication (PMTIC), Chèques et Formation agricole.

49 Parlement wallon, Projet de décret modifiant le décret du 6 novembre 2008 portant rationalisation de la fonction consultative et diverses dispositions relatives à la fonction consultative, $n^{\circ} 601 / 1,4$ octobre 2016, p. 3 . 


\section{LA FONCTION CONSULTATIVE WALLONNE AVANT LA RÉFORME DE 2017}

Ce deuxième chapitre explore le paysage de la fonction consultative wallonne, dont la principale composante est le Conseil économique et social de Wallonie (CESW). La première section présente les instances consultatives voisines du cas wallon, à savoir les conseils économiques et sociaux bruxellois, flamand et des Communautés française et germanophone. L'évolution du cadre institutionnel belge et de la répartition des compétences entre les entités fédérées joue un rôle déterminant sur le contenu des missions de ces instances. La seconde section étudie de manière plus détaillée le CESW ainsi que les autres instances consultatives qui, avec celui-ci, forment l'ensemble de la fonction consultative wallonne. Cette section dépeint la situation antérieure à la réforme de 2017.

\subsection{PRÉALABLE : LE DÉCOUPAGE INSTITUTIONNEL DE LA FONCTION CONSULTATIVE RÉGIONALE ET COMMUNAUTAIRE}

Dans son aspect formel tel qu'étudié ici, la fonction consultative régionale et communautaire se manifeste à travers le travail d'une série d'instances créées par décret (ou par ordonnance dans le cas bruxellois). Les instances consultatives régionales ont précédé les instances consultatives communautaires et ont un spectre d'intervention plus large que ces dernières. Cela s'explique notamment par le fait que la fonction consultative s'est historiquement construite autour des conseils économiques régionaux et des interlocuteurs sociaux dans une perspective de développement économique régional.

\subsubsection{Les Conseils économiques et sociaux régionaux (Wallonie, Bruxelles, Flandre)}

Les trois Régions du pays disposent de leurs propres instances consultatives, qui sont également chargées de certaines missions de concertation. À l'inverse de leurs homologues fédéraux, le Conseil central de l'économie (CCE) et le Conseil national du travail (CNT), les conseils économiques et sociaux (CES) traitent conjointement, comme leur nom l'indique, des matières économiques et sociales. Il s'agit, en Wallonie, du Conseil économique et social de Wallonie (CESW), en Région bruxelloise, du Conseil économique 
et social de la Région de Bruxelles-Capitale (CESRBC) et, en Flandre, du SociaalEconomische Raad van Vlaanderen (SERV).

Des trois organismes, le CESRBC est celui dont la création est la plus récente : il a été institué par l'ordonnance bruxelloise du 8 septembre $1994^{50}$. Pour sa part, le SERV a été créé par le décret flamand du 27 juin $1985^{51}$ (depuis lors abrogé et remplacé par un décret du 7 mai $2004^{52}$ ). Il abrite différents « conseils d'avis stratégiques» correspondant aux compétences de la Flandre. Par ailleurs, il est lui-même le conseil d'avis stratégique reconnu pour les matières relevant de l'économie, de l'emploi et de l'économie sociale, de l'énergie (dans sa dimension économique) et de la politique gouvernementale («regeringsbeleid»).

Les trois CES régionaux partagent la caractéristique commune de rassembler des représentants des interlocuteurs sociaux. Du côté des travailleurs, il s'agit des responsables régionaux des organisations syndicales reconnues comme représentatives au niveau national. Du côté des employeurs, il s'agit des organisations patronales des secteurs marchand et non marchand reconnues comme représentatives pour chaque niveau régional, auxquelles s'ajoutent les organisations de classes moyennes ainsi que, sauf pour le CESRBC, les organisations agricoles. En revanche, le CESW se distingue du CESRBC et du SERV par le fait qu'il remplit des missions conjointes de consultation et de concertation. À Bruxelles et en Flandre, la fonction de concertation tripartite est organisée respectivement par le Comité bruxellois de concertation économique et sociale (CBCES) ${ }^{53}$ et par le Vlaams Economisch Sociaal Overlegcomité (VESOC) ${ }^{54}$.

Les différents CES régionaux sont amenés à se rencontrer et à collaborer. À certaines occasions, les instances fédérales, à savoir le CCE et le CNT, demandent l'avis des CES régionaux sur certaines thématiques, avis qu'ils joignent à leur propre remise d'avis. Un tel processus peut également être nécessaire lorsque l'une des deux instances consultatives fédérales est sollicitée pour une remise d'avis par l'Union européenne.

Les différents CES régionaux, auxquels s'adjoint dans ce cas le CES de la Communauté germanophone (cf. infra), se rencontrent environ une fois par an et formulent parfois des positions communes. Cela a notamment été le cas suite à l'accord institutionnel du 11 octobre 2011 sur la sixième réforme de l'État, qui contenait le projet d'importants transferts de compétences vers les entités fédérées et a amené les présidents des CES à appeler à un maximum de coordination dans les processus de transfert et à un maximum de concertation avec les interlocuteurs sociaux. À cette occasion, les présidents des CES ont également affirmé que le rôle historique de consultation et de concertation des CES s'appliquerait également aux nouvelles compétences transférées ${ }^{55}$.

\footnotetext{
Moniteur belge, 6 décembre 1994.

Moniteur belge, 3 juillet 1985.

Moniteur belge, 25 août 2004.

Créé par arrêté du gouvernement de la Région de Bruxelles-Capitale du 16 janvier 1997 (Moniteur belge, 11 avril 1997).

54 Créé par arrêté de l'exécutif flamand du 17 juillet 1985 (Moniteur belge, 7 septembre 1985).

Conseil économique et social de la Région de Bruxelles-Capitale (CESRBC), Conseil économique et social de Wallonie (CESW), Sociaal-Economische Raad van Vlaanderen (SERV), Wirtschafts- und Sozialrat der Deutschsprachigen Gemeinschaft Belgiens (WSR), « Déclaration commune. Transferts de compétences : Principes généraux adoptés par les Conseils économiques et sociaux des entités fédérées ", 9 janvier 2013, www.cesw.be.
} 


\subsubsection{Le Conseil économique et social de la Communauté française}

Le Conseil économique et social de la Communauté française (CESCF) a été créé par le décret du 24 octobre $2008^{56}$. Sa mise en place a coïncidé avec le renouvellement des membres du CESRW, le 27 mai $2009^{57}$. Issu d'une demande des interlocuteurs sociaux wallons et bruxellois francophones ainsi que du gouvernement de la Communauté française, le CESCF est l'interlocuteur du Parlement et du gouvernement de la Communauté française. Il est chargé de formuler des avis au sujet des compétences de la Communauté française ayant une incidence sur les matières économiques et sociales, telles que l'enseignement ou la santé.

Le CESCF se singularise par son absence de personnalité juridique, car le gouvernement de la Communauté française n'a "pas voulu créer une institution de plus mais faciliter et organiser le dialogue entre les partenaires sociaux régionaux interprofessionnels sur les grandes orientations que prend la Communauté française ${ }^{58}$. Son secrétariat est confié à l'administration (le secrétariat général du Ministère de la Communauté française), et ce contrairement au souhait des interlocuteurs sociaux qui avaient proposé un secrétariat conjoint CESW-CESRBC.

Depuis son institution, le CESCF s'est peu réuni et semble être tombé en désuétude. Lorsque le besoin de consulter les interlocuteurs sociaux se fait sentir, le gouvernement de la Communauté française a pris l'habitude de consulter parallèlement les CES wallon et bruxellois.

\subsubsection{Le Conseil économique et social de la Communauté germanophone}

Aucun mécanisme ne garantit la représentation des intérêts particuliers de la région de langue allemande dans les instances législative et exécutive de la Région wallonne ${ }^{59}$. En revanche, l'existence d'une commission spéciale germanophone (toujours en vigueur après la réforme de la fonction consultative de 2017, cf. infra) au sein du CESW est actée dans le décret wallon du 25 mai 1983. De plus, trois membres de l'assemblée générale du CESW (sur 50) et un membre du bureau (sur 16) doivent être domiciliés dans une commune de la région de langue allemande.

Outre cette représentation germanophone au CESW, il existe un CES propre à la Communauté germanophone : le Wirtschafts- und Sozialrat der Deutschsprachigen Gemeinschaft Belgiens (WSR). Réunissant également les interlocuteurs sociaux, le WSR a été créé par un décret de la Communauté germanophone du 26 juin $2000{ }^{60}$, lorsque la Région wallonne a transféré à la Communauté germanophone l'exercice de compétences

\footnotetext{
Moniteur belge, 3 décembre 2008.

CESRW, « Rapport d'activités 2009 », p. 144-145.

Parlement de la Communauté française, Projet de décret portant création du Conseil économique et social de la Communauté française, $\mathrm{n}^{\circ}$ 570/1, 27 juin 2008, p. 3 .

F. BOUHON, C. NIESSEN, M. ReuCHAMPS, « La Communauté germanophone après la sixième réforme de l'État : état des lieux, débats et perspectives », Courrier hebdomadaire, CRISP, n 2266-2267, 2015, p. 59.

Moniteur belge, 11 octobre 2000.
} 
en matière de placement ${ }^{61}$ en région de langue allemande (ce type de transfert étant permis par l'article 139 de la Constitution). Suite à la sixième réforme de l'État, qui a régionalisé des compétences supplémentaires en matière d'emploi et de placement, la Région wallonne a procédé à un nouveau transfert d'exercice de compétences à la Communauté germanophone. Le WSR se prononce également sur les questions d'emploi et de formation touchant aux intérêts de la Communauté germanophone.

Le WSR et la commission spéciale germanophone du CESW ont une composition quasiment similaire. Le WSR se réunit environ une fois par mois et la commission spéciale germanophone du CESW une fois tous les deux mois. Les mois où se réunit la commission spéciale germanophone du CESW, le WSR se réunit directement après, les deux réunions s'enchaînant.

\subsection{LE CONSEIL ÉCONOMIQUE ET SOCIAL DE WALLONIE}

L'étude du fonctionnement du CESW permet de comprendre les caractéristiques de la fonction consultative wallonne. Trois missions sont attribuées au CESW par le décret du 25 mai 1983, à savoir rendre des avis, organiser la concertation et assurer le secrétariat des conseils spécialisés.

\subsubsection{Le champ d'intervention}

Le CESW est compétent pour rendre des avis et des recommandations sur toutes les matières qui relèvent des compétences de la Région wallonne - que celle-ci les possède en propre ou les exerce suite à un accord avec la Communauté française - ou qui ont une incidence sur la vie économique et sociale de la Wallonie. Les matières qui font l'objet d'accords de coopération ${ }^{62}$ entre la Région wallonne et la Communauté française peuvent également faire l'objet d'une remise d'avis.

La force de la fonction consultative ne se puise pas dans la conflictualité, mais plutôt dans la collaboration entre les parties en présence (outre, bien sûr, dans la représentativité de celles-ci). Celles-ci doivent tenter d'identifier leurs intérêts communs et de les transmettre à l'autorité publique par la remise d'avis. Le but est de dégager des positions consensuelles entre elles. Plus les positions reprises dans l'avis sont unanimes, plus elles sont susceptibles d'exercer une influence sur le processus de prise de décision ${ }^{63}$. Dans les cas où il n'a pas été possible de dégager un avis unanime, les positions des différentes parties sont précisées dans le document d'avis ${ }^{64}$.

${ }^{61}$ C’est-à-dire « les services privés et publics qui interviennent pour suivre et accompagner les chômeurs dans leurs recherches d'emploi » (V. KAISER, L. SIMAR, "Les politiques d'emploi en Wallonie après la sixième réforme de l'État ", Les dossiers du Conseil, CESW, décembre 2015, p. 7).

62 Sur cette notion, cf. J.-G. LOWIES, M.-H. SCHROBILTGEN, « L'accord de coopération culturelle entre la Communauté française et la Communauté flamande ", Courrier hebdomadaire, CRISP, n² 2293-2294, 2016, p. 7-13.

63 É. ARCQ, La concertation sociale, op. cit., p. 44

64 Dans le jargon du CESW, ce cas de figure est appelé « fourchette ». 
Formellement, le CESW est compétent pour remettre des avis, soit à la demande du gouvernement wallon (en la personne d'un ou de plusieurs ministres) soit d'initiative. Généralement, c'est dans le cas où le CESW estime ne pas avoir été consulté à tort qu'il formule un avis d'initiative. Dans certaines circonstances, le ministre a l'obligation de demander un avis au CESW. Mais elles sont rares : de manière générale, il n'existe pas d'obligation de consultation ${ }^{65}$. Toutefois, dans les faits, le CESW est presque toujours consulté sur les matières économiques et sociales. Le ministre n'est pas non plus tenu de suivre l'avis qui lui est remis par le CESW, ni même de justifier l'absence de prise en compte.

La phase consultative est celle qui s'ouvre avec la demande d'avis et se referme lors de la remise de celui-ci. Lorsqu'elle concerne des textes à portée législative, elle se déroule généralement entre la première et la deuxième lecture des avant-projets de décret par le gouvernement wallon. Elle est parfois précédée d'une phase de consultation plus informelle avec certaines instances ou certains acteurs en particulier. Cette phase consultative ne concerne pas uniquement le CESW : toute instance consultative et tout organisme d'intérêt public (tel que le FOREM) peut être amené à être consulté. Une fois la phase de consultation formelle clôturée, l'avant-projet de décret est modifié, le cas échéant, sur la base des avis reçus par le ministre. L'avant-projet de décret est alors soumis à l'ensemble du gouvernement wallon en deuxième lecture, puis est soumis à l'avis du Conseil d'État. À ce stade, il arrive que des avis parviennent encore au ministre. Après réception de l'avis du Conseil d'État et éventuelle modification, le gouvernement wallon soumet le texte au Parlement wallon, sous la forme d'un projet de décret.

\subsubsection{Les structures : assemblée générale, bureau, commissions internes et groupes de travail}

Plusieurs types d'organes composent le CESW : l'assemblée générale, le bureau, les commissions internes et les groupes de travail.

Tous ces organes sont composés des interlocuteurs sociaux, répartis sur une base paritaire. Les représentants des travailleurs sont les responsables wallons des trois organisations syndicales reconnues comme représentatives au niveau fédéral : la Confédération des syndicats chrétiens de Belgique (CSC), la Fédération générale du travail de Belgique (FGTB) et, depuis 2005, la Centrale générale des syndicats libéraux de Belgique (CGSLB) ${ }^{66}$. Les fédérations d'employeurs, quant à elles, sont organisées sur une base régionale et représentent l'ensemble des secteurs économiques selon un impératif d'intersectorialité : l'Union wallonne des entreprises (UWE), l'Entente wallonne de classes moyennes (hébergée et gérée par l'Union des classes moyennes - UCM), la Fédération wallonne de l'agriculture (FWA), l'Union des entreprises à profit social (UNIPSO) depuis $2005^{67}$

65 Cette situation est très différente de celles qui prévalent en Région de Bruxelles-Capitale et en Flandre.

6 À l'exception du bureau, où seules la CSC et la FGTB siègent du côté syndical.

Anciennement Union francophone des entreprises non marchandes (UFENM). L'UNIPSO est représentée à l'assemblée générale du CESW depuis 2005 et au bureau depuis 2011, suite à un accord avec l'UCM qui lui cède l'un de ses sièges. 
et le Syndicat neutre pour indépendants (SNI) depuis $2017^{68}$. Les membres siégeant à l'assemblée générale du CESW sont nommés par arrêté du gouvernement wallon, pour une durée de quatre ans, sur la base de listes fournies par les organisations représentatives de travailleurs et d'employeurs.

L'assemblée générale du CESW dispose d'un pouvoir formel important en matière consultative : celui d'avaliser les avis entérinés par le bureau. C'est en son sein que se mènent également des discussions plus transversales sur la manière dont le CESW doit orienter son travail afin de remplir au mieux ses missions ${ }^{69}$. En outre, l'assemblée générale dispose d'un droit d'approbation sur certaines nominations de personnel, ainsi que sur la gestion des comptes par le bureau. L'assemblée générale se compose de 50 membres (25 pour chacun des deux bancs). À l'origine, le décret du 25 mai 1983 prévoyait la désignation directe de deux fois 20 membres et la cooptation d'entre 6 et 10 membres supplémentaires. Ensuite, le décret du 30 avril $2009^{70}$ a augmenté le nombre de membres désignés à deux fois 25 personnes et a mis fin à la pratique de la cooptation. Le nombre de membres de chaque organisation représentative est négocié entre les interlocuteurs sociaux puis est fixé par le gouvernement wallon lors des renouvellements. La répartition des sièges dévolus aux organisations représentatives de travailleurs entre celles-ci est déterminée par le résultat des élections sociales. Il est à noter que, le CESW s'étant conformé au décret wallon du 15 mai 2003 promouvant la présence équilibrée d'hommes et de femmes dans les instances consultatives ${ }^{71}$ - qui préconise la présence de maximum deux tiers de membres d'un même sexe au sein d'une instance consultative -, le nombre de femmes membres de l'assemblée générale s'est accru, passant de 5 à 18 en 2005.

Le bureau est l'instance exécutive du CESW. Il assure la gestion des commissions internes et entérine les avis au nom de l'assemblée générale. Il est composé de 14 représentants, dont 7 sont issus des organisations représentatives de travailleurs et 7 des organisations représentatives d'employeurs, élus par l'assemblée générale. Chaque banc désigne également un expert. Le secrétaire général et les deux secrétaires généraux adjoints du CESW participent aux réunions du bureau. Le président est désigné pour un mandat de deux ans; suivant un principe d'alternance en vigueur depuis 1996, il est issu alternativement du banc syndical et du banc patronal.

Le bureau du CESW joue un rôle pivot dans la procédure de remise d'avis. La procédure est la suivante : le bureau reçoit les demandes d'avis et les transfère à la commission interne qu'il juge adéquate, celle-ci prépare un projet d'avis, qu'elle soumet ensuite au bureau. Une fois approuvé par celui-ci, l'avis est envoyé au ministre concerné. Pour sa part, l'assemblée générale ratifie les avis lors de ses réunions. Cependant, celle-ci ne se réunissant pas régulièrement, il n'est pas toujours envisageable d'attendre sa ratification avant de transmettre l'avis au ministre, sous peine d'être hors délais (hors cas d'urgence, la procédure de consultation prévoit 35 jours entre la demande et la remise de l'avis).

68 Depuis le renouvellement de l'assemblée générale le 23 mai 2017. Le SNI fait donc partie de l'assemblée générale et potentiellement des commissions internes au CESW, mais pas du bureau.

69 CESW, « Rapport d'activités 2016 », p. 18.

70 Décret wallon du 30 avril 2009 modifiant le décret du 25 mai 1983 modifiant, en ce qui regarde le Conseil économique régional pour la Wallonie, la loi-cadre du 15 juillet 1970 portant organisation de la planification et de la décentralisation économique et instaurant un Conseil économique et social de la Région wallonne, Moniteur belge, 15 mai 2009.

71 Moniteur belge, 20 mai 2003. Ce décret est aujourd'hui abrogé et remplacé par le décret wallon du 27 mars 2014. 
Dès lors, le bureau se charge d'adopter les avis des commissions internes de manière provisoire. Outre la remise d'avis, le bureau du CESW assure également d'autres fonctions, dont la mission de concertation tripartite en rencontrant des représentants du gouvernement wallon. Ce sont également les membres du bureau qui représentent politiquement le CESW et qui définissent le travail à effectuer, en fonction des orientations définies au sein de l'assemblée générale.

Les commissions internes au CESW, bien qu'elles ne revêtent aucun statut formel, constituent le cœur de la fonction consultative. C'est en effet en leur sein qu'est réalisé le travail quotidien de débat entre les interlocuteurs sociaux, de formulation de positions et de rédaction d'avis. Les commissions internes sont constituées sur une base thématique et leur création relève de l'organisation interne du CESW. Elles peuvent faire appel à des experts et inviter des représentants du gouvernement ou de l'administration afin d'éclairer ses délibérations. Elles doivent s'adapter à l'actualité des dossiers traités. Dès lors, il leur arrive, lorsque cela s'avère pertinent, de travailler conjointement. Le nombre des commissions internes et leur objet sont reconsidérés et, le cas échéant, modifiés lors du renouvellement de la composition des différentes instances du CESW, c'est-à-dire tous les quatre ans. Avant la réforme opérée en 2017, les commissions internes au CESW sont au nombre de neuf et leur liste est la suivante ${ }^{72}$ :

- Commission Action-Intégration sociale-Services collectifs-Santé (AIS) ;

- Commission Conservation de la nature-Environnement-Ruralité-Agriculture (CERA) ;

- Commission Économie-Politiques industrielles (EPI) ;

- Commission Emploi-Formation-Éducation (EFE);

- Commission Énergie ;

- Commission Finance-Institutionnel-Simplification administrative (FIS) ;

- Commission Mobilité-Aménagement du territoire (MAT) ;

- Commission Villes-Logement-Équipement-Sécurité (VLES);

- Commission spéciale germanophone.

Selon les dossiers, des groupes de travail peuvent également être créés. De la même forme que les commissions internes, ils n'en ont cependant pas le caractère permanent : ils sont amenés à disparaître lorsqu'aboutit le dossier dont ils ont été chargés (par exemple, la sixième réforme de l'État ou la formation continue pour les travailleurs).

S'ajoute également le Conseil de la politique scientifique (CPS), dont les travaux portent sur la recherche scientifique en Région wallonne. Créée en 1990, cette instance a un statut particulier : elle n'est ni une commission interne composée de manière paritaire, ni un conseil spécialisé dont les avis sont pris de manière autonome (cf. infra). D’une part, elle ressemble aux commissions internes d'un point de vue procédural, puisque ses avis doivent être entérinés par le bureau avant d'être transmis au gouvernement. Mais, d'autre part, sa composition l'apparente à un conseil spécialisé, puisqu'elle rassemble, outre les interlocuteurs sociaux, des représentants des universités, des hautes écoles et de l'administration. Cette configuration hybride a inspiré l'élaboration de la réforme de la fonction consultative menée en 2017.

72 CESW, « Rapport d'activités 2016 », p. 24. 
Le personnel du secrétariat du CESW est composé d'environ 70 employés, qui relèvent de la catégorie «fonctionnaires para-régionaux de type B ». Ce personnel est soumis à un statut particulier pour garantir son indépendance. Par exemple, le processus de recrutement est organisé de manière autonome par l'assemblée générale et le bureau.

Le fonctionnement du CESW est financé par le budget régional wallon. Chaque organisation membre du bureau dispose en outre d'un budget supplémentaire pour assurer sa mission de concertation ${ }^{73}$.

\subsubsection{Les conseils spécialisés}

Le décret du 25 mai 1983 assigne au CESW la mission d'assurer le secrétariat de conseils spécialisés. À la veille de la réforme de 2017, il existe plus d'une trentaine de conseils spécialisés logés au sein du CESW ${ }^{74}$. Ils sont présentés ici par ordre alphabétique :

- Comité de contrôle de l'eau (CContrEau);

- Comité d'experts chargés de l'examen des demandes d'agrément de systèmes d'épuration individuelle ;

- Comité d'orientation en matière d'accompagnement des reconversions ;

- Commission d'agrément des auteurs de projets (CAAP);

- Commission d'agrément Congé-éducation payé ;

- Commission d'avis sur les recours en matière d'urbanisme (CAR);

- Commission Chèques (agrément des opérateurs de formation en matière de chèques-formation);

- Commission CISP (agrément à destination des centres d'insertion socioprofessionnelle - CISP);

- Commission consultative d'agrément des entreprises titres-services ;

- Commission consultative et d'agrément des entreprises d'économie sociale (COMES) ;

- Commission consultative et de concertation en matière de placement (COPLA) ;

- Commission consultative de l'eau (CCE);

- Commission consultative Fonds de formation titres-services ;

- Commission consultative scientifique pour les produits agro-alimentaires (CCSPA) ;

- Commission des déchets (CDD);

- Commission Formation agricole ;

- Commission PMTIC (agrément à destination des organismes de formation relevant du Plan mobilisateur des technologies de l'information et de la communication - PMTIC) ;

73 Ce budget supplémentaire octroyé aux organisations membres du bureau provient également du budget régional wallon afférent aux compétences du ministre-président. Cf., par exemple, «Budget initial 2017. Dotation complémentaire aux organisations membres du bureau du Conseil économique et social de Wallonie », http://spw.wallonie.be.

74 CESW, « Rapport d'activités $2016 »$, p. 71. 
- Commission régionale d'aménagement du territoire (CRAT) ;

- Commission régionale d'avis pour l'exploitation des carrières (CRAEC) ;

- Commission royale des monuments, sites et fouilles de la Région wallonne (CRMSF) ;

- Conseil consultatif de la formation en alternance (CCFA);

- Conseil supérieur wallon de l'agriculture, de l'agro-alimentaire et de l'alimentaire (CSWAAA) ;

- Conseil supérieur wallon de la chasse (CSWC);

- Conseil supérieur wallon de la conservation de la nature (CSWCN);

- Conseil supérieur wallon des forêts et de la filière bois (CSWFFB);

- Conseil supérieur wallon de la pêche (CSWP);

- Conseil wallon de l'économie sociale (CWES);

- Conseil wallon de l'égalité entre hommes et femmes (CWEHF);

- Conseil wallon de l'environnement pour le développement durable (CWEDD);

- Observatoire du commerce.

S'y ajoutent en outre :

- le Conseil de la politique scientifique (CPS, cf. supra);

- 8 commissions de conservation des sites Natura 2000 :

- Commission de conservation d'Arlon;

- Commission de conservation de Dinant ;

- Commission de conservation de Liège ;

- Commission de conservation de Malmedy ;

- Commission de conservation de Marche-en-Famenne ;

- Commission de conservation de Mons ;

- Commission de conservation de Namur ;

- Commission de conservation de Neufchâteau.

Le CESW met à la disposition de ces instances un support logistique en termes de personnel, d'appui technique et d'infrastructure. Le budget nécessaire au fonctionnement des conseils spécialisés provient d'une dotation générale ainsi que, pour chaque conseil spécialisé, de budgets spécifiques venant du ministre compétent et affectés au CESW. Les conseils spécialisés concentrent leurs discussions autour de thématiques délimitées (par exemple, les titres-services, l'aménagement du territoire, etc.). Leur spectre d'intervention et leurs fonctions précises sont définis par décret.

À la différence des commissions internes, les conseils spécialisés sont créés par le gouvernement wallon (et non par le CESW). Certains d'entre eux, comme la Commission royale des monuments, sites et fouilles de la Région wallonne (CRMSF), existent depuis plus longtemps que le CESW lui-même. La composition d'un conseil spécialisé fait l'objet de négociations lors de la création de celui-ci et à chaque renouvellement de ses sièges. Outre les interlocuteurs sociaux, des organisations issues de la société civile occupent une partie des sièges, dans une proportion variable selon les conseils spécialisés. Par exemple, la moitié des sièges du Conseil wallon de l'égalité entre hommes et femmes 
(CWEHF) est occupée par les interlocuteurs sociaux, et l'autre moitié par des organisations représentatives de la thématique: le Conseil des femmes francophones de Belgique (CFFB), les Femmes prévoyantes socialistes (FPS), Vie féminine, etc. Contrairement aux organisations dont sont issus les interlocuteurs sociaux - qui sont formellement reconnues comme représentatives et qui ne changent donc pas dans la durée--, différentes organisations de la société civile peuvent entrer en concurrence pour être représentées dans un conseil spécialisé donné. À chaque renouvellement de l'instance, c'est au ministre compétent qu'il revient d'arrêter la liste des organisations qui y siégeront désormais. En fonction de leurs missions, les conseils spécialisés peuvent également avoir comme membres des représentants de l'administration, d'organismes d'intérêt public (OIP) ou de pouvoirs locaux (par exemple, dans la Commission des déchets - CDD).

Les matières régionales sur lesquelles un conseil spécialisé est amené à rendre des avis sont précisées dans le décret qui fonde celui-ci. Les conseils spécialisés disposent également d'une prérogative de remise d'avis d'initiative. Dans certains cas, la remise d'un avis par un conseil spécialisé est obligatoire ; ainsi, le Comité de contrôle de l'eau (CContrEau) doit nécessairement être consulté avant toute modification de prix de l'eau. Au-delà des remises d'avis sur certaines thématiques définies, les conseils spécialisés peuvent remplir d'autres types de missions, la plus courante étant la remise d'avis relativement à des agréments. C'est le cas de la Commission CISP, dont le rôle est d'évaluer les demandes d'agrément, de renouvellement d'agrément, de suspension d'agrément ou de retrait d'agrément lorsque des dossiers relatifs à des centres d'insertion socio-professionnelle (CISP) s'avèrent litigieux ${ }^{75}$. Les différents types de missions peuvent également s'additionner. Par exemple, le Conseil consultatif de la formation en alternance (CCFA) est compétent pour se prononcer sur des demandes d'agrément de formations en alternance en plus de donner des avis au gouvernement en matière de formation en alternance. Dans d'autres cas, à l'inverse, ces missions relatives à une thématique similaire sont réparties entre des conseils spécialisés distincts. Ainsi, le Conseil wallon de l'économie sociale (CWES) remet des avis au gouvernement sur les matières touchant à l'économie sociale en Wallonie, tandis que la Commission consultative et d'agrément des entreprises d'économie sociale (COMES) est une instance à caractère plutôt administratif, où il ne s'agit pas de débattre mais d'accorder des agréments à des entreprises de l'économie sociale (entreprises d'insertion, initiatives de développement de l'emploi dans le secteur des services de proximité à finalité sociale, agences-conseils en économie sociale) sur la base de critères prédéterminés - dont la nature n'est pas discutée à la COMES mais bien au CWES. La composition des deux organes est presque analogue.

Les demandes d'avis de la part d'un ministre au cours du processus consultatif peuvent s'adresser à plusieurs conseils spécialisés simultanément, ainsi qu'au CESW. Le fait d'être logé au sein du CESW a des conséquences concrètes dans pareille situation. Si le CESW et un ou plusieurs conseils spécialisés sont saisis de demandes d'avis identiques, cela provoque une différence de temporalité dans les discussions et dans la formulation d'avis. En effet, les commissions internes au CESW se réunissant plus régulièrement que les conseils spécialisés (en raison de leur volume de travail), les interlocuteurs sociaux ont l'opportunité de délibérer rapidement entre eux au sujet de l'avis demandé. Or ces mêmes interlocuteurs sociaux sont en outre membres des conseils spécialisés auxquels un avis

75 Pour le détail des missions de cette instance, cf. « Commission CISP », www.cesw.be. 
est également demandé. Lorsque les conseils spécialisés se réunissent à leur tour, les demandes d'avis ont donc déjà été discutées par les interlocuteurs sociaux au sein du CESW, de sorte que la marge de discussion au sein de ces instances est moindre. Les organisations de la société civile présentes dans les conseils spécialisés mais pas au CESW doivent composer avec la position préexistante adoptée par le CESW, ce qui augmente le risque de positions divergentes exprimées dans l'avis. Ce dernier est en effet susceptible de contenir, d'une part, la/les position(s) des interlocuteurs sociaux et, d'autre part, celle(s) des autres organisations représentées. De plus, certaines positions exprimées se retrouvent dans plusieurs avis, provoquant des doublons dans les avis reçus par le ministre ou le gouvernement.

\subsection{LES AUTRES TYPES DE CONSULTATION}

Si le nombre important de conseils spécialisés, aux dénominations multiples, a déjà été canalisé une première fois dans le cadre des décrets portant rationalisation de la fonction consultative adoptés en 2008, il s'est agi plutôt alors d'une harmonisation du fonctionnement entre ces conseils. En dehors de cela, le foisonnement d'instances consultatives reste une réalité.

Il existe en effet d'autres instances consultatives (commissions, conseils, etc.) qui fonctionnent hors du giron du CESW et dont la mission est également de conseiller le gouvernement wallon. C'est le cas du Conseil wallon de l'évaluation, de la prospective et de la statistique (CWEPS), dont le secrétariat est assuré par l'Institut wallon de l'évaluation, de la prospective et de la statistique (IWEPS) et qui réunit des membres issus du CESW, du Conseil wallon de l'environnement pour le développement durable (CWEDD, qui est un conseil spécialisé déjà mentionné supra) et des membres des corps scientifique, académique ou assimilé des institutions d'enseignement universitaire ou supérieur. Le fait que certaines des instances d'avis soient situées en dehors du CESW explique que les interlocuteurs sociaux soient parfois absents de leur composition. Par exemple, les interlocuteurs sociaux sont désignés comme représentants du CESW au CWEPS, au Conseil général de l'énergie et au Conseil wallon de l'action sociale et de la santé (CWASS), mais ils sont absents du Conseil supérieur du tourisme ${ }^{76}$.

La fonction consultative existe également entre la Région wallonne et les pouvoirs locaux, par le biais du Conseil supérieur des villes, communes et provinces de la Région wallonne (CSVCP), créé en 1993. Parmi les organisations constitutives du CSVCP, l'Union des villes et communes de Wallonie (UVCW) est également membre de certains conseils spécialisés situés sous la coupole du CESW (par exemple, la Commission régionale d'avis pour l'exploitation des carrières - CRAEC) ou en dehors de celle-ci (par exemple, le Conseil supérieur du logement - CSL).

76 Ces trois dernières instances sont rattachées à l'administration wallonne : le Conseil général de l'énergie à la Direction générale opérationnelle de l'Aménagement du territoire, du Logement, du Patrimoine et de l'Énergie (DGO4); le CWASS à la Direction générale opérationnelle des Pouvoirs locaux et de l'Action sociale (DGO5) ; le Conseil supérieur du tourisme au Commissariat général au tourisme (CGT). 


\section{LE PROCESSUS DE RÉFORME DE LA FONCTION CONSULTATIVE WALLONNE (2014-2017)}

Ce chapitre expose le déroulement de la dernière réforme en date de la fonction consultative wallonne, à savoir celle de 2017, et présente les principaux changements ayant affecté la structure et le fonctionnement du CESW par rapport à la situation décrite dans le chapitre 2 . Les sections s'enchaînent de manière chronologique, afin de retracer le processus ayant conduit à l'adoption de la réforme, tout en mettant en lumière les interventions d'acteurs ayant contribué à la prise de décision. La première section revient sur les racines de la nouvelle réforme, qui puise son existence dans la première «rationalisation » de la fonction consultative opérée en 2008 (cf. supra), dont elle modifie les décrets. C'est donc d'une modification des décrets du 6 novembre 2008 dont il sera question, et non du décret du 25 mai 1983 constitutif du CESW. La deuxième section détaille le processus de réforme, en présentant les différentes étapes de la prise de décision et les éléments de fond ayant été discutés par les différentes parties prenantes lors de chacune de celles-ci. La troisième section présente l'architecture de la fonction consultative réformée, ainsi que quelques éléments de la période d'après-réforme.

Ce chapitre est aussi l'occasion d'illustrer la fonction consultative en action, puisque le processus de réforme s'est opéré non seulement en étroite concertation entre le gouvernement wallon et les interlocuteurs sociaux, mais aussi avec des interventions d'autres instances consultatives et organisations de la société civile.

\subsection{L'ORIGINE DE LA RÉFORME}

Plusieurs types d'acteurs étaient partisans d'une nouvelle réforme de la fonction consultative wallonne: certains partis politiques, les interlocuteurs sociaux et des organisations de la société civile ont formulé clairement cette volonté à l'aube de la législature régionale 2014-2019. Celle-ci a été l'occasion pour le nouveau gouvernement wallon formé en juillet 2014 - c'est-à-dire le gouvernement Magnette (PS/CDH) d'inscrire le projet de réforme dans sa déclaration de politique régionale. 


\subsubsection{Les appels des acteurs}

Si les appels à une réforme sont nombreux, les programmes que les partis politiques francophones élaborent en vue des élections multiples du 25 mai 2014 (fédérales, régionales et européennes) contiennent peu de propositions relatives à la fonction consultative ou même aux relations à entretenir avec la société civile organisée au sens large.

Le PS évoque la participation de la société civile aux niveaux local et européen. En ce qui concerne le niveau régional, il prône un renforcement de la concertation sociale, dans le cadre notamment de la mise en œuvre à venir de la sixième réforme de l'État. Le MR n'aborde pas non plus le sujet directement. Pour lui, les dispositifs consultatifs doivent plutôt se tourner vers les citoyens et la nouvelle législature wallonne doit adopter les décrets pour mettre en place la consultation populaire régionale. Le programme du MR ne mentionne pas de propositions transversales en matière de fonction consultative. Il se limite à en appeler ponctuellement à une meilleure consultation des acteurs (sectoriels), notamment dans les domaines de la mobilité et de la chasse. Écolo traite de la thématique par l'angle de la transparence et de la publicité des travaux de l'exécutif. Le programme écologiste propose de renforcer le contrôle parlementaire sur le pouvoir exécutif, notamment en organisant la publicité des avis rendus aux gouvernements dans le cadre de la fonction consultative et en améliorant le suivi de l'action des organismes d'intérêt public. Seul le CDH mentionne explicitement la mise en place d'une réforme de la fonction consultative dans son programme électoral. Une double motivation anime cette proposition : opérer une distinction entre les instances d'avis et les instances de gestion, et obliger les autorités publiques à indiquer la manière dont elles ont pris en compte les avis remis par les instances consultatives.

Du côté des acteurs socio-économiques, les interlocuteurs sociaux wallons ont appelé à plusieurs reprises, depuis les années 1990, à diverses réformes de la fonction consultative. En 2014, ils rédigent un mémorandum dans lequel ils soulèvent la problématique des nouvelles matières qui seront transférées suite à l'adoption de la sixième réforme de l'État : « Pour le CESW, le transfert des compétences est l'occasion de réexaminer l'organisation de la fonction consultative en Wallonie, tant pour les matières qui relèvent déjà de la compétence des entités fédérées que pour celles qui sont nouvellement transférées " ${ }^{77}$, écrivent-ils.

Pour les organisations de la société civile, les périodes électorales sont également l'occasion de publier des mémorandums afin d'exposer leurs priorités aux futurs élus. Pour ce qui a trait à leur participation à la consultation en matière de prise de décision politique, ces organisations entendent démontrer leur représentativité et assurer leur place dans les processus consultatifs qui les concernent. La précédente réforme de 2008 ayant laissé certaines de ces organisations sur leur faim, elles réclament dès lors une nouvelle réforme de la fonction consultative. Par exemple, dans une partie de son mémorandum régional de 2013, Inter-Environnement Wallonie (IEW) formule des propositions pour « associer pleinement les forces vives de la société civile et réformer la fonction consultative ${ }^{78}$. Du côté des pouvoirs locaux, l'Union des villes et communes de Wallonie (UVCW)

77 CESW, «Mémorandum du CESW 2014-2019. Les champs d'action prioritaires pour la Wallonie », s.d. [2014], www.cesw.be, p. 11.

IEW, « Mémorandum régional 2013 », septembre 2013, www.iewonline.be, p. 46. 
appelle les futures autorités régionales à « renforcer le dialogue et la concertation (...) de sorte qu'ait lieu une consultation et une concertation active avec les communes en amont de toute décision ${ }^{79}$.

\subsubsection{Le lancement de la réforme}

Constitué le 22 juillet 2014, le gouvernement Magnette s'accorde, lors de sa formation, sur la nécessité de réformer la fonction consultative wallonne, afin d'en rendre l'organigramme plus lisible et de faciliter l'efficacité de la prise de décision. Le projet est annoncé dans la déclaration de politique régionale du gouvernement, le 23 juillet 2014 : «Le gouvernement entend amplifier les actions visant à faire de la Wallonie un modèle de gestion efficace au service de ses citoyens et de ses entreprises. Il entend (...) mener (...) une rationalisation de la fonction consultative en réduisant significativement le nombre d'organismes, en en simplifiant leur fonctionnement et en améliorant leur représentativité démocratique ${ }^{80}$.

Le nouveau ministre-président wallon, Paul Magnette (PS), avait été l'un des acteurs de la réforme entérinée en 2008, en tant que ministre de la Santé, de l'Action sociale et de l'Égalité des chances du gouvernement Demotte I (cf. supra). N'étant resté à ce poste que quelques mois (à savoir de juillet 2007 jusqu'à décembre de la même année), il n'avait alors, selon ses termes, "pas pu mener cette réforme à bien ${ }^{81}$.

À quelques nuances près, les objectifs annoncés en juillet 2014 s'apparentent à ceux de la réforme de 2008: réduction du nombre d'organismes, simplification du fonctionnement, amélioration de la représentativité démocratique. La réforme a un caractère transversal ; en effet, elle porte sur la structure, l'architecture de la fonction consultative, au-delà du fonctionnement de chaque instance prise indépendamment. Dès lors, la réforme est menée sous la conduite du ministre-président, en collaboration avec chaque ministre (notamment pour ce qui est de l'évaluation et de la recension des instances consultatives utilisées). P. Magnette fait également appel au CESW, et plus particulièrement au Groupe des partenaires sociaux wallons (GPSW, cf. infra), pour que celui-ci propose au gouvernement une nouvelle architecture pour la fonction consultative wallonne. Cette sollicitation s'inscrit dans la démarche de P. Magnette de développer un "modèle social wallon » (ou «modèle mosan ») de concertation avec les interlocuteurs sociaux en Wallonie. En effet, le ministre-président souhaite faire évoluer des pratiques jusque-là essentiellement consultatives "vers un véritable régime de concertation, de négociation et même, dans un certain cas, pratiquement de codécision ", notamment à travers une réforme en profondeur des organes consultatifs ${ }^{82}$.

79 «Mémorandum régional, communautaire, fédéral et européen 2014 », Mouvement communal, UVCW, $95^{\mathrm{e}}$ année, $\mathrm{n}^{\circ} 885$, janvier 2014, p. 30.

Go Gouvernement wallon, «Oser, innover, rassembler », Déclaration de politique régionale, 23 juillet 2014, p. 93.

Parlement wallon, Compte rendu intégral, $\mathrm{n}^{\circ} 14,15$ février 2017, p. 71.

Parlement wallon, Compte rendu intégral, $\mathrm{n}^{\circ} 37,16$ novembre 2015, p. 2. 


\subsection{LE PROCESSUS DÉCISIONNEL}

Le processus de la réforme de la fonction consultative tient les parties prenantes en haleine pendant plus de deux années et demie, entre l'annonce de juillet 2014 (dans la déclaration de politique régionale) et l'adoption des décrets réformés en février 2017. Une première phase consiste à rassembler les forces vives, leur expertise et leurs idées. Cette étape s'achève pendant l'été 2015. Le gouvernement wallon travaille alors à l'élaboration de deux avant-projets de décret, destinés à modifier les deux décrets portant rationalisation de la fonction consultative adoptés en 2008 (l'un pour les matières régionales, l'autre pour les compétences communautaires dont l'exercice a été transféré à la Région wallonne par la Communauté française). Les avant-projets de décret suscitent beaucoup de réactions chez les acteurs concernés, et la phase de consultation et de modification des textes prend une année supplémentaire. Finalement, le gouvernement Magnette statue sur les projets de décret et les transmet au Parlement wallon en octobre 2016. Différents débats sont prolongés dans l'arène parlementaire et se concluent finalement par l'adoption des décrets réformés, le 15 février 2017.

\subsubsection{L'état des lieux et les premières propositions}

Le gouvernement Magnette se tourne sans tarder vers les interlocuteurs sociaux, «les professionnels de la consultation » - qui, par ailleurs, soutiennent pleinement l'ambition de la réforme (cf. supra) -, afin qu'ils dessinent les contours du nouveau modèle de fonction consultative.

\section{Les propositions du Groupe des partenaires sociaux wallons (16 mars 2015)}

C'est le Groupe des partenaires sociaux wallons (GPSW) ${ }^{83}$ qui se retrouve à la manœuvre pour élaborer un premier projet. En effet, il est chargé par P. Magnette d'imaginer le futur paysage de la fonction consultative wallonne. Le ministre-président wallon déclarera au début de l'année 2015: "Je leur ai indiqué que l'on pouvait, pour ma part, faire vraiment tabula rasa. On peut faire comme si la fonction consultative wallonne n'existait pas et que l'on allait, aujourd'hui, l'inventer ${ }^{84}$.

Le GPSW a été constitué en 2013 à l'initiative des interlocuteurs sociaux, sur le modèle du Groupe des dix au niveau fédéral ${ }^{85}$. Eu égard à la sixième réforme de l'État, il a en

3 Également parfois dénommé Groupe des partenaires sociaux de Wallonie (GPS-W).

Parlement wallon, Compte rendu intégral, $\mathrm{n}^{\circ} 57,5$ janvier 2015, p. 20.

Le Groupe des dix est une instance informelle de concertation interprofessionnelle au niveau fédéral, au sein de laquelle se rencontrent les interlocuteurs sociaux ( 5 représentants des syndicats - à savoir 2 de la Confédération des syndicats chrétiens de Belgique (CSC), 2 de la Fédération générale du travail de Belgique (FGTB) et 1 de la Centrale générale des syndicats libéraux de Belgique (CGSLB) - et 5 représentants des employeurs - à savoir 2 de la Fédération des entreprises de Belgique (FEB), 1 de l'Unie van Zelfstandige Ondernemers (UNIZO, l'association chrétienne flamande des classes moyennes et des indépendants), 1 de l'Union des classes moyennes (UCM) et 1 du Boerenbond) sous la présidence d'un représentant de la FEB. Le Groupe des dix négocie différents accords, ainsi que, généralement tous les deux ans, un accord interprofessionnel (AIP). La mise en œuvre des accords conclus au sein 
effet semblé utile qu'il y ait en Wallonie un équivalent de ce qu'est, à l'échelle du pays, le Groupe des dix. Suivant les pratiques de ce dernier, le GPSW est une instance informelle, qui n'est donc instituée par aucun décret. Le but poursuivi par la création du GPSW est d'assurer un espace de négociation aux interlocuteurs sociaux wallons et d'octroyer à ceux-ci la capacité de négocier des accords « à part entière », c'est-à-dire des accords qui devront être respectés par le gouvernement wallon ${ }^{86}$. Outre cette fonction de négociation, le GPSW est amené à participer activement aux réflexions relatives à la réforme de la fonction consultative wallonne. Il est à noter à ce propos qu'il existe des liens entre le GPSW et le CESW : les organisations membres du GPSW sont identiques à celles du bureau du CESW et le secrétaire général du CESW assiste aux réunions du GPSW, tandis que le GPSW s'appuie en partie sur les ressources du CESW pour assurer son secrétariat. Les propositions formulées par le GPSW sur la nouvelle mouture de la fonction consultative sont d'ailleurs remises au gouvernement Magnette, le 16 mars 2015, sous la forme d'un avis du CESW ${ }^{87}$.

Les points principaux de cet avis répondent aux objectifs de réduction, de simplification et d'amélioration de la fonction consultative exposés par le gouvernement wallon. Il y est en effet proposé de réduire le nombre total d'instances, en créant une nouvelle structure comportant des «pôles» thématiques. Cette réforme s'effectuerait en regroupant les instances existantes et aurait pour bénéfice de diminuer le nombre total de mandats, ainsi que de pallier le manque d'homogénéité entre les instances de consultation. Elle constituerait également un moyen de lutter contre l'absentéisme des membres dans les instances consultatives (phénomène dû notamment aux multiples mandats représentatifs de certains d'entre eux).

Le projet de réforme érige le CESW en structure faittière centrale, qui dirigerait les demandes d'avis vers des pôles thématiques. Cela aurait pour effet attendu de simplifier les procédures de demande et de remise d'avis, en réduisant les doublons, déplorés par plusieurs acteurs, et en remettant au gouvernement wallon des "avis uniques». Le document indique: "Le nouveau principe de fonctionnement signifierait qu'un même avis ne soit demandé qu'à une ou plusieurs structures de la fonction consultative. Dans cette hypothèse, le CESW assurerait l'organisation des travaux menant à un seul avis. Cela signifie que, soit il remet lui-même un avis, soit il transmet la demande à une structure qui associe aux interlocuteurs sociaux désignés par le CESW d'autres acteurs wallons dès lors que ce dossier pourrait y être traité plus efficacement. Le CESW transmet l'avis issu d'une structure de la fonction consultative dans sa version intégrale, il lui est loisible d'apporter les compléments ou de formuler toutes observations qu'il juge utiles ».

Cette proposition de réorganisation reste dans la lignée des missions assignées au CESW en matière de fonction consultative par le décret du 25 mai 1983. En effet, le CESW continuerait, en tant qu'instance consultative, à formuler des avis sur les matières économiques et sociales (c'est-à-dire relevant de l'emploi, de la formation, etc.) à l'aide de ses commissions internes en ce qui concerne les dossiers qui relèvent de la Commission

du Groupe des dix requiert l'adoption de lois ou de conventions collectives de travail (CCT) au niveau $\mathrm{du}$ Conseil national du travail (CNT). Cf. P. BLAISE, «Le cadre institutionnel de la concertation sociale ", in É. ARCQ et al. (dir.), Dynamiques de la concertation sociale, op. cit., p. 53.

${ }^{86}$ Cf., par exemple, la négociation du Pacte pour l'emploi et la formation en Wallonie, signé le 30 mai 2016 par le gouvernement wallon et les interlocuteurs sociaux.

CESW, Avis n A.1210, 16 mars 2015. 
Emploi-Formation-Éducation (EFE), de la Commission Économie-Politiques industrielles (EPI) et de la Commission Finance-Institutionnel-Simplification administrative (FIS). Outre cette mission d'avis, le CESW continuerait à assurer sa mission de secrétariat, mais celle-ci s'effectuerait désormais à destination de divers pôles thématiques qui remplaceraient les conseils spécialisés. L'avis précise : «Chacun de ces pôles sera composé de 16 à 24 membres effectifs et de 16 à 24 membres suppléants. $50 \%$ (8 à 12) des membres représentent les interlocuteurs sociaux désignés par le CESW ; les autres membres seront des acteurs représentatifs de la société civile en Wallonie (...). Ces pôles auront une autonomie d'organisation et la possibilité de s'entourer, si besoin en est, d'experts ou d'opérateurs qui ont une connaissance pointue et pratique utile à la construction d'un avis ; chaque membre effectif pourra se faire accompagner d'un expert ».

La proposition articulant la structure faîtière CESW avec des pôles thématiques prend pour modèle le Conseil de la politique scientifique (CPS, cf. supra). Il s'agit d'un organe dont la composition rassemble à la fois les interlocuteurs sociaux et différentes parties prenantes à la thématique de la politique scientifique ${ }^{88}$. Il développe ses avis de manière autonome, mais ceux-ci sont formellement entérinés par le bureau du CESW avant d'être transmis au gouvernement wallon ${ }^{89}$. Les avis rendus par le CPS sont ainsi repris dans le catalogue des avis rendus par le CESW ${ }^{90}$.

Les pôles thématiques suggérés dans ce premier avis sont au nombre de six. Ils sont les suivants : «Politique scientifique », « Aménagement du territoire », «Environnement », « Nature, Agriculture, Ruralité », «Mobilité » et «Action sociale ». Par ailleurs, il est proposé à ce stade que la réforme laisse intacts les quelques conseils spécialisés, en nombre réduit, qui ne pourraient trouver de place dans un de ces six pôles thématiques en raison de spécificités qui empêchent d'envisager un regroupement: le Comité de contrôle de l'eau (CContrEau), la Commission régionale d'avis pour l'exploitation des carrières (CRAEC), la Commission royale des monuments, sites et fouilles de la Région wallonne (CRMSF), le Conseil wallon de l'économie sociale (CWES) et l'Observatoire du commerce.

Le principe des pôles poursuivra son chemin dans la réforme, le nombre, la terminologie et la liste des thématiques de ceux-ci évoluant au fur et à mesure des étapes du processus de décision.

En ce qui concerne les commissions d'agrément, le GPSW admet que cette fonction relève plutôt de l'administration. En revanche, il propose que les commissions d'agrément qui relèvent de matières touchant à l'emploi et la formation soient maintenues au CESW en raison de l'expertise de celui-ci sur ces matières. Les autres commissions d'agrément sont renvoyées dans le giron de l'administration wallonne. Enfin, le GPSW entend protéger le principe de l'autonomie des instances consultatives en supprimant l'existence de sièges avec voix délibérative qui sont dévolus, dans certaines instances (principalement des

88 Né en 1990, le CPS est lui-même le résultat d'une rationalisation, puisqu'il procède d'une fusion entre la Commission Politique de recherche et innovation technologique du CESRW et le Conseil supérieur des technologies nouvelles (CSTN).

89 Dans les faits, le CPS semble bénéficier d'une importante autonomie en ce qui concerne également la remise de ses avis : en pratique, ceux-ci sont toujours automatiquement validés par le bureau du CESW. Par ailleurs, le comité de liaison qui se réunit en cas de désaccord entre le CPS et le bureau du CESW sur un avis ne s'est réuni que cinq fois en l'espace de 25 ans (cf. "Conseil politique scientifique. Présentation. Liens avec le CESW », www.cesw.be).

90 Cf. «Conseil politique scientifique. Les avis», www.cesw.be. 
commissions d'agrément, par exemple la Commission CISP ou le Comité d'orientation en matière d'accompagnement des reconversions), aux représentants politiques et aux représentants de l'administration et des organismes d'intérêt public.

\section{L'inventaire des instances consultatives régionales}

Concomitamment à la demande qu'adresse le ministre-président au GPSW, les différents ministres du gouvernement wallon sont invités à procéder chacun à un inventaire des instances consultatives avec lesquelles ils sont amenés à interagir : conseils, commissions et autres comités (y compris les instances qui seront transférées depuis le niveau fédéral ou la Communauté française dans le cadre de la mise en œuvre de la sixième réforme de l'État). Cette recension doit aussi inclure les instances consultatives qui ont été créées par décret ou arrêté mais qui n'ont jamais été effectivement mises en œuvre (par exemple, le Comité consultatif des transports publics de personnes par route, créé par un arrêté du gouvernement wallon en date du 8 juillet 1993 mais jamais installé). Doit y être également inclus un état des lieux de chacune des instances: missions, coût, organisation interne et plus-value.

Afin d'établir ce cadastre, les différents ministres wallons consultent plusieurs des instances et organisations avec lesquelles ils travaillent dans le cadre de leurs compétences ${ }^{91}$. Certaines d'entre elles profitent de l'occasion que leur offre cette sollicitation pour adresser au ministre-président P. Magnette leur avis au sujet du dossier de la réforme (ainsi que leurs réactions aux propositions du GPSW). D'autres instances et organisations adressent d'initiative leurs positions à des ministres de tutelle spécifiques et au ministre-président ${ }^{92}$. Dans l'ensemble, ces différents avis approuvent la volonté de réforme de la fonction consultative, tout en insistant sur l'importance de conserver les spécificités sectorielles (le fait qu'il existe différents degrés de consultation, allant du plus technique au plus général, est relevé) et de préserver la représentation des acteurs composant les instances actuelles.

\section{La note d'orientation du gouvernement wallon (23 juillet 2015)}

Ce conséquent travail de recension, ainsi que les propositions formulées par le GPSW dans l'avis rendu par le CESW, mènent à la rédaction d'une note d'orientation rédigée par le cabinet du ministre-président P. Magnette, qui est remise au gouvernement wallon le 20 juillet 2015. Cette note a préalablement été présentée aux interlocuteurs sociaux et discutée par ceux-ci cinq jours plus tôt.

91 Par exemple, dans le domaine de l'environnement et de l'aménagement du territoire, la Commission consultative de l'eau (CCE), la Commission des déchets (CDD), la Commission régionale d'aménagement du territoire (CRAT), la Commission régionale d'avis pour l'exploitation des carrières (CRAEC) et le Conseil wallon de l'environnement pour le développement durable (CWEDD) sont sollicités par le ministre wallon en charge de l'Environnement, Carlo Di Antonio $(\mathrm{CDH})$; il leur demande d'aboutir à une position conjointe sur l'état de la fonction consultative et sur le projet de réforme (tel que proposé par le GSPW dans l'avis rendu par le CESW le 16 mars 2015). Ces instances échouent à s'accorder sur une position commune ; dès lors, elles remettent chacune un avis au ministre C. Di Antonio ainsi qu'au ministre-président P. Magnette.

92 Tel est, par exemple, le cas de l'Association des agences de développement territorial wallonnes (Wallonie développement) et du Conseil supérieur wallon de la conservation de la nature (CSWCN). 
La note au gouvernement wallon du 20 juillet 2015 détaille la première phase de la méthodologie du processus de réforme, à savoir l'entreprise de recensement « au sens large », par les membres du gouvernement, des structures consultatives. En l'occurrence, 135 instances ont ainsi été répertoriées. La note les répartit en catégories, selon leur fonction première: commissions consultatives à caractère générique, commissions consultatives à caractère technique, commissions d'avis sur les agréments, commissions d'avis sur les recours, commissions d'avis sur l'octroi des primes, organes de régulation ayant la faculté de remettre des avis d'initiative.

La note préconise de concentrer la réforme sur les instances consultatives à caractère générique, c'est-à-dire celles qui "ont notamment pour mission la remise d'avis, d'observations, de suggestions, de propositions ou de recommandations soit d'initiative, soit à la demande du gouvernement wallon sur des problématiques spécifiques ou sur des avant-projets de décrets et d'arrêtés relatifs aux différentes compétences wallonnes ». Les autres instances seront redirigées vers l'administration, ou maintenues en l'état si la fonction consultative ne constitue pas leur activité principale.

La fonction consultative générique se retrouvant au cour des activités d'une trentaine d'instances listées, il s'agira donc désormais d'intégrer celles-ci à la nouvelle architecture basée sur des pôles thématiques. À cet égard, le nombre de pôles et la répartition des thématiques entre ceux-ci ont évolué entre les propositions du GPSW du 16 mars 2015 et la note au gouvernement wallon du 20 juillet 2015. Cette dernière propose de créer huit pôles, dont quatre seraient mono-thématiques («Politique scientifique », « Mobilité », «Social», «Environnement») et quatre autres seraient pluri-thématiques ( Aménagement du territoire, Patrimoine», "Secteurs économiques spécifiques", «Ruralité, Nature, Chasse, Pêche», "Énergie, Logement»). Cette nouvelle proposition de l'organisation en pôles permet d'y intégrer les conseils spécialisés précédemment laissés intacts (cf. supra), à deux exceptions près : la CRAEC (dont le renvoi vers la DGO3 du SPW est préconisé car ses missions ne correspondent pas à la fonction consultative générique) et le CContrEau (qui est laissé à l'identique comme "conseil spécialisé " logé au sein du CESW).

Le 23 juillet 2015, le gouvernement Magnette approuve la note d'orientation présentée par le ministre-président wallon, s'accordant ainsi sur la délimitation du périmètre de la réforme et sur les balises de la future architecture de la fonction consultative.

\subsubsection{Les débats autour des avant-projets de décret}

Après l'adoption de la note d'orientation du gouvernement wallon, celui-ci, toujours sous l'égide du cabinet du ministre-président, poursuit ses travaux afin d'élaborer les avantprojets de décret qui permettront d'aboutir aux projets de décret réformant la fonction consultative wallonne. Ces avant-projets de décret seront approuvés par le gouvernement wallon en première lecture le 17 décembre 2015, en deuxième lecture le 9 juin 2016 et en troisième lecture le 29 septembre 2016. Chacune de ces étapes continuera à être rythmée, d'une part, par un dialogue étroit avec les interlocuteurs sociaux, via le CESW, et, d'autre part, par des interpellations en provenance des instances consultatives appelées à être réformées et de certaines des organisations qui y siègent. 


\section{La première lecture}

Suite à l'approbation de la note d'orientation par le gouvernement wallon, le CESW remet un nouvel avis, destiné à préciser la nature de la réforme, le 28 septembre $2015^{93}$. Le CESW y détaille, pour chaque aspect de la réorganisation de la fonction consultative générique envisagée à ce stade, les changements ou statu quo qu'il préconise pour chaque instance en termes de place dans l'architecture générale (intégration à un pôle, à l'administration ou autre), de composition et de missions.

D'autres instances consultatives réagissent à plusieurs reprises en formulant des prises de position pendant la phase de travail menant aux avant-projets de décret : la Commission consultative de l'eau (CCE), la Commission régionale d'aménagement du territoire (CRAT), le Conseil wallon de l'environnement pour le développement durable (CWEDD), la Commission royale des monuments, sites et fouilles de la Région wallonne (CRMSF), les huit commissions de conservation des sites Natura 2000, etc. Tel est également le cas d'organisations de la société civile et de représentants de pouvoirs locaux, par exemple l'Union des villes et communes de Wallonie (UVCW) et Inter-Environnement Wallonie (IEW). La mobilisation est forte.

Parallèlement à cela, certaines organisations se sont rassemblées dès le début du processus de réforme au sein d'une plate-forme afin de donner plus de poids à leurs revendications : IEW, Aquawal (union professionnelle des opérateurs publics du cycle de l'eau en Wallonie), ConcertES (plate-forme de concertation des organisations représentatives de l'économie sociale), Fédération des parcs naturels de Wallonie (FPNW), Natagora (association de protection de la nature), Ressources (fédération des entreprises d'économie sociale actives dans la réduction des déchets par la récupération, la réutilisation, la valorisation et le recyclage des ressources), Union nationale des agrobiologistes belges (UNAB). Ces organisations adressent leurs positions conjointes au ministre-président en mai 2015 et en octobre 2015 et rencontrent ce dernier le 16 octobre 2015. Elles expriment le souhait de voir des représentants des différents futurs pôles siéger dans la structure faitière aux côtés des interlocuteurs sociaux, moyennant un renouvellement régulier pour des questions de représentativité. Ce faisant, les organisations de la plateforme réclament un maximum d'autonomie pour les futurs pôles dans l'élaboration de la remise d'avis, revendiquant que la structure faitière serve essentiellement d'instance de coordination et d'appui. Elles expriment aussi leur désir de voir toutes les commissions internes au CESW être ouvertes à l'ensemble des représentants de la société civile.

De leur côté, certaines instances consultatives se montrent sceptiques quant à leur intégration future à un pôle. Par exemple, deux conseils spécialisés, à savoir la Commission régionale d'aménagement du territoire (CRAT) et le Conseil wallon de l'environnement pour le développement durable (CWEDD), critiquent le principe et la notion de pôle, arguant que cela complexifierait la structure plutôt que de la simplifier. Leur démarche sera vaine, puisque le gouvernement wallon maintiendra la proposition initiale des interlocuteurs sociaux et instituera donc les pôles (cf. infra).

La question du poids de la structure faîtière et de l'autonomie des futurs pôles est soulevée par différents acteurs tout au long du processus de réforme, notamment en lien avec le

93 CESW, Avis n ${ }^{\circ}$ A.1243, 28 septembre 2015. 
projet de remise d'un avis unique. À chaque fois, le ministre-président P. Magnette et les interlocuteurs sociaux répondent en précisant que la structure faitière n'aura pas vocation à modifier les avis mais à les compléter (selon le principe du codicille) ${ }^{94}$. En outre, dans les débats relatifs à l'élargissement de la structure, ils rappellent et mettent en avant la professionnalisation et la représentativité intersectorielle des interlocuteurs sociaux par rapport à d'autres organisations de la société civile.

À l'issue de cette première phase de travail, le cabinet du ministre-président rédige la première version des deux avant-projets de décret. Le premier texte concerne les matières dont l'exercice a été transféré à la Région wallonne par la Communauté française. Il est centré sur l'organisation d'un pôle «Action sociale et intégration ». Il prévoit également le transfert du Conseil supérieur du tourisme vers le pôle pluri-thématique «Secteurs économiques spécifiques", ainsi que le maintien de certaines commissions d'agrément sous la coupole du CESW (par exemple, la Commission CISP). Le second texte est relatif aux matières régionales. Il a trait aux autres instances consultatives et aux pôles alors projetés dans ce cadre. Ces pôles sont dorénavant au nombre de sept : « Politique scientifique ", «Mobilité », «Environnement», «Aménagement du territoire, Patrimoine », "Secteurs économiques spécifiques », "Ruralité, Nature, Chasse, Pêche », «Énergie, Logement». Certains de ces pôles sont alors mono-thématiques et d'autres pluri-thématiques ; cette distinction sera abandonnée entre la première et la deuxième lecture des avant-projets de décret par le gouvernement wallon, à la suite de remarques des interlocuteurs sociaux et d'autres organisations de la société civile (cf. infra).

Les deux avant-projets de décret sont approuvés en première lecture par le gouvernement wallon, le 17 décembre 2015.

\section{La deuxième lecture}

Un nouvel avis, portant sur les deux avant-projets de décret, est sollicité auprès du CESW, qui le remet le 29 janvier $2016^{95}$. Le CESW y estime que, si les pôles mono-thématiques s'apparentent à une vraie rationalisation, les pôles pluri-thématiques apparaissent, à l'inverse, comme une juxtaposition des structures existantes, ce qui les amènerait à manquer de cohérence. Par exemple, le pôle pluri-thématique "Secteurs économiques spécifiques » intégrerait à la fois le Conseil supérieur wallon de l'agriculture, de l'agroalimentaire et de l'alimentation (CSWAAA), le Conseil supérieur wallon des forêts et de la filière bois (CSWFFB), le Conseil wallon de l'économie sociale (CWES), le Conseil supérieur du tourisme et l'Observatoire du commerce. L'alternative qui sera dégagée par la suite consistera à réorganiser certains pôles mono-thématiques en plusieurs sections (cf. infra).

L'avis du CESW suggère également de retravailler certaines définitions, afin qu'elles correspondent le plus exactement possible à la réalité et au cadrage de la réforme. Par

94 En vocabulaire notarié, le codicille désigne l'acte de modifier partiellement un testament. Appliqué à la remise d'avis dans la fonction consultative, cela signifie que la structure faîtière, composée des interlocuteurs sociaux, serait compétente pour compléter les avis formulés au sein des pôles. De cette manière, l'objectif de remise d'avis unique reste atteint, mais cet avis pourrait comporter des ajouts, nuances, voire divergences d'opinions, émises par la structure faîtière en addition à l'avis initialement rédigé par le pôle concerné.

CESW, Avis n A.1267, 29 janvier 2016. 
exemple, le CESW propose que soit révisée la définition qui est donnée de la fonction consultative générique dans les avant-projets de décret. En l'occurrence, ceux-ci définissent la fonction consultative générique comme «la mission de remise d'avis, portant d'une part sur des textes à portée générale ou des notes d'orientation du gouvernement, et d'autre part sur des avant-projets de décret ainsi que sur des dispositions ayant une portée réglementaire ». Pour sa part, le CESW propose que soient précisées la provenance de la demande d'avis (en y ajoutant la saisine parlementaire) et la nature de ceux-ci, en indiquant que la fonction consultative générique "consiste, à la demande du gouvernement, du Parlement ou d'initiative, à remettre des avis, des réflexions, des études, à formuler des observations, des suggestions, des propositions ou des recommandations sur des notes d'orientation du gouvernement d'une part et, d'autre part, sur des avantprojets de décret et sur les projets d'arrêtés ou autres dispositions ayant une portée réglementaire ».

Dans cet avis, le CESW estime aussi que la proportion de sièges que les avant-projets de décret envisagent de réserver aux interlocuteurs sociaux au sein des futurs pôles est injustement faible. Le CESW concède que la clé de répartition 50/50 entre interlocuteurs sociaux et organisations de la société civile pourrait être adaptée dans certains pôles, selon leur thématique, afin d'y laisser plus de place à la société civile (par exemple, en y tendant vers un rapport 40/60). Mais, en règle générale pour ce qui a trait à la composition des pôles, le CESW considère que les interlocuteurs sociaux devraient s'y voir octroyer une "place significative ». L'argument qu'il met en avant est le fait que les interlocuteurs sociaux ont eux-mêmes proposé de créer des pôles dans des domaines où la participation de la société civile est opportune et amène une plus-value à la consultation. De plus, le CESW accepte d'externaliser vers les pôles (et donc vers la société civile) des travaux qui se déroulaient auparavant dans les commissions internes au CESW.

Dans son avis, le CESW propose également que soit abandonnée l'idée de créer un pôle "Action sociale et intégration " ${ }^{96}$. L'Agence wallonne pour une vie de qualité (AVIQ), instituée le $1^{\text {er }}$ janvier 2016 - c'est-à-dire au cours du processus de réforme de la fonction consultative wallonne -, est en effet dotée d'un Conseil de stratégie et de prospective, chargé d'assurer la fonction consultative sur les matières gérées par ce nouvel organe. À ce propos, le CESW soulève l'incongruité du principe de confier la fonction consultative à un organisme d'intérêt public (OIP) sur ses propres missions. En effet, le fait que l'organisation des travaux et du secrétariat de la consultation incombe à l'instance elle-même lui semble contraire au principe de l'autonomie de la fonction consultative. En réalité, la mise en place de l'AVIQ et de ses organes se situe hors du cadre de la réforme de la fonction consultative wallonne. Elle y touche néanmoins indirectement, puisque le Conseil de stratégie et de prospective de l'AVIQ absorbe une partie des missions du Conseil wallon de l'action sociale et de la santé (CWASS) sous la forme de quatre des sept commissions de celui-ci (à savoir les commissions Santé, Famille, Aînés et Personnes handicapées). Pour sa part, le CESW suggère de ne pas créer de pôle "Action sociale et intégration ", puisque celui-ci serait redondant avec le Conseil de stratégie et de prospective de l'AVIQ, mais de conserver au sein du CESW la fonction consultative sur les matières concernées. Concrètement, le CESW prendrait en charge

96 Relativement à cette thématique spécifique, le CESW remet également une proposition complémentaire au gouvernement wallon le 19 avril 2016. 
les matières relatives à l'intégration sociale qui ne relèvent pas de l'AVIQ (comme l'accueil et l'hébergement des sans-abri, le surendettement, etc.).

Enfin, le CESW note que les avant-projets de décret ne mentionnent ni ne définissent la catégorie des "conseils spécialisés ", alors même que celle-ci était présente dans la note d'orientation du gouvernement wallon du 23 juillet 2015. En conséquence, certaines instances ne sont pas prises en compte dans la nouvelle architecture proposée. Par exemple (peut-être suite à un simple oubli), il n'est prévu de place nulle part pour le Comité de contrôle de l'eau (CContrEau) ; le CESW préconise de le placer parmi les « conseils spécialisés ${ }^{97}$.

Suite à la multitude d'autres avis reçus ${ }^{98}$, le gouvernement wallon procède à la préparation de la deuxième lecture des deux avant-projets de décret. Pour cela, différents aspects des avis reçus (de la part de l'ensemble des acteurs) sont repris dans une note et résumés en propositions ou contre-propositions.

Sur cette base, le gouvernement wallon retravaille les avant-projets de décret et formule une nouvelle version de l'architecture de la fonction consultative.

D'une part, il maintient l'appellation et le concept de "pôle », qui sont prônés par le CESW mais qui ont été critiqués par d'autres instances (notamment la CRAT et le CWEDD, au motif que cela consiste à agréger les instances existantes sans simplifier la fonction consultative, cf. supra).

D'autre part, le gouvernement wallon procède à un remaniement des pôles, en abandonnant les pôles pluri-thématiques. En effet, il propose dorénavant de créer sept pôles mono-thématiques, regroupés autour de la structure faîtière qu'est le CESW : "Politique scientifique », " Mobilité », «Énergie », «Logement », " Aménagement du territoire », «Environnement » et « Ruralité ».

Ce recentrement sur la logique mono-thématique provoque l'éclatement du pôle plurithématique "Secteurs économiques spécifiques", un temps envisagé, en cinq "conseils spécialisés ", qui seraient quant à eux gérés par une coupole avec secrétariat au sein du CESW car inclassables dans les pôles. Il s'agit de la Commission royale des monuments, sites et fouilles de la Région wallonne (CRMSF), du Conseil supérieur du tourisme, du Conseil wallon de l'économie sociale (CWES), du Conseil wallon de l'égalité entre hommes et femmes (CWEHF) et de l'Observatoire du commerce, qui seraient donc maintenus tels quels. L'idée d'intégrer le Comité de contrôle de l'eau (CContrEau) - comme l'a suggéré le CESW (cf. supra) - à cette liste de conseils spécialisés n'est pas suivie à ce stade par le gouvernement ; le CContrEau y sera toutefois ajouté dans les avant-projets de décret effectivement adoptés en deuxième lecture.

97 Cela était d'ailleurs déjà préconisé dans la note d'orientation au gouvernement wallon du 20 juillet 2015 (cf. supra).

98 Ces avis émanent des organes suivants : IEW, les 15 janvier et 9 mars; UVCW, le 18 janvier ; Fédération des CPAS, le même jour; Conseil des recteurs (CREF, qui réunit les recteurs des institutions universitaires établies en Communauté française), le 28 janvier ; Nature, terres et forêts (NTF, association des propriétaires ruraux de Wallonie), le même jour ; Commission consultative de l'eau (CCE), le 5 février ; Aquawal, le même jour ; Commission régionale d'aménagement du territoire (CRAT), le 9 février; Conseil wallon de l'environnement pour le développement durable (CWEDD), le 10 février; Conférence permanente des intercommunales wallonnes de gestion des déchets (COPIDEC), le 12 février; Commission royale des monuments, sites et fouilles de la Région wallonne (CRMSF), le 10 mars; les huit commissions de conservation des sites Natura 2000, le même jour. 
Trois pôles, bien que mono-thématiques, seraient pourvus de plusieurs sections: le pôle «Aménagement du territoire » (deux sections : "Aménagement régional » et "Aménagement opérationnel»), le pôle "Environnement» (trois sections : «Eau », « Déchets », «Sols ») et le pôle " Ruralité » (cinq sections : « Nature», "Chasse », « Pêche », « Forêt et filière bois », « Agriculture et agro-alimentaire »).

La note indique en outre qu'il sera permis que certains pôles aient des fonctions mixtes (fonction consultative générale et fonction consultative technique), au nom d'un certain pragmatisme quant à leurs missions. En revanche, elle confirme que les instances purement techniques seront intégrées à l'administration.

L'hypothèse de l'ouverture de la structure faitière - comprenant les différentes commissions internes au CESW - aux représentants des différents pôles, telle que revendiquée par la plate-forme d'acteurs essentiellement environnementaux (cf. supra), n'est pas suivie par le gouvernement wallon. Celui-ci maintient le CESW, composé des interlocuteurs sociaux, comme interlocuteur du gouvernement pour les matières touchant à l'économie et à l'emploi et comme porte d'entrée des demandes et des remises d'avis. Il précise toutefois que le CESW devra transmettre les avis rédigés par les pôles dans leur version intégrale, et que toute éventuelle modification apportée par la structure faîtière devra figurer dans un avis complémentaire (en référence au droit d'initiative octroyé au CESW par le décret du 25 mai 1983). Les pôles sont également autorisés à remettre des avis d'initiative ainsi que, s'ils le souhaitent, à travailler ensemble pour élaborer des avis conjoints.

La revendication du CESW visant à ce que soit attribuée aux interlocuteurs sociaux une part significative des sièges composant les pôles n'est pas nécessairement suivie (à l'exception du pôle "Politique scientifique»). Il en résulte que les interlocuteurs sociaux se retrouvent en infériorité numérique dans la plupart des pôles.

Un autre point abordé dans les avant-projets de décret à ce stade et relatif à la composition des pôles concerne la présence de représentants du gouvernement et de l'administration. Il est prévu d'exclure l'attribution de sièges à des membres du gouvernement, ceux-ci pouvant simplement être invités afin de présenter un projet. Quant à elle, la présence de membres de l'administration (ou d'organismes d'intérêt public) est considérée comme nécessaire dans certains cas, voire parfois centrale (par exemple, sur les questions d'aménagement du territoire, la Société publique d'aide à la qualité de l'environnement - SPAQUE). Le gouvernement prévoit donc de leur permettre de siéger avec voix délibérative.

Concernant les matières sociales, le gouvernement wallon décide de suivre la recommandation du CESW d'abandonner l'idée de créer un pôle "Action sociale et intégration ». Il décide que ces matières seront prises en charge à deux niveaux de la fonction consultative. D'une part, au sein du Conseil de stratégie et de prospective de l'AVIQ. D'autre part, au sein de l'une des commissions internes au CESW : la Commission Action-Intégration sociale-Services collectifs-Santé (AIS), qui remet des avis, d'initiative ou à la demande du gouvernement wallon, sur tous les avant-projets de décret relatifs aux matières sociales. À cet égard, le gouvernement wallon décide par ailleurs que, lorsque la fonction consultative s'exerce dans les matières relatives à la politique de l'action sociale au sens strict ou à la politique de l'intégration des personnes étrangères et d'origine étrangère, le CESW associera à cette Commission AIS, en fonction de la politique 
concernée, soit une section "Action sociale » soit une section «Intégration des personnes étrangères ou d'origine étrangère » (l'une et l'autre composées de représentants autres que les interlocuteurs sociaux).

Pour ce qui a trait à la fonction consultative avec les pouvoirs locaux, les avant-projets de décret identifient trois interlocuteurs à part entière (fonctionnant donc en dehors de la création d'une instance particulière) : l'Union des villes et communes de Wallonie (UVCW), la Fédération des centres publics d'action sociale (Fédération des CPAS) - qui est un organe de l'UVCW - et l'Association des provinces wallonnes (APW).

Enfin, la note du gouvernement wallon préparant la deuxième lecture des avant-projets de décret comprend une définition de la fonction consultative générique, qui sera reprise à l'article $2 / 1, \$ 2$, du décret: "La fonction consultative est la mission consistant à remettre des avis, à formuler des observations, des suggestions, des propositions ou des recommandations, à la demande du gouvernement, du Parlement ou d'initiative, portant d'une part, sur des notes d'orientation du gouvernement ou sur des textes à portée générale ou stratégique et, d'autre part, sur des avant-projets de décrets ou d'arrêtés à portée réglementaire $"$ ". Cette définition s'inspire donc fortement de celle suggérée par le CESW (notamment, elle intègre le principe de la saisine parlementaire), mais elle ne la reprend pas telle quelle.

Ces différentes modifications sont donc intégrées dans les deux avant-projets de décret, qui sont adoptés en deuxième lecture par le gouvernement wallon le 9 juin 2016.

\section{La troisième lecture}

Le lendemain, 10 juin 2016, le ministre-président sollicite l'avis du Conseil d'État sur les deux avant-projets de décret. La haute juridiction administrative remet son avis le 18 juillet $2016^{100}$. Les remarques formulées dans cet avis sont principalement d'ordre légistique ou appellent à préciser certains propos ${ }^{101}$.

Ces observations du Conseil d'État sont majoritairement suivies par le gouvernement wallon, qui adapte les avant-projets de décret en conséquence et qui adopte ceux-ci en troisième lecture le 29 septembre 2016.

99 Décret wallon du 16 février 2017 modifiant le décret du 6 novembre 2008 portant rationalisation de la fonction consultative et diverses dispositions relatives à la fonction consultative, Moniteur belge, 5 avril 2017.

100 À la même date, le CESW remet également un avis concernant la terminologie juridique des avant-projets de décret (CESW, Avis n ${ }^{\circ}$ A.1301, 18 juillet 2016).

101 Par exemple, le Conseil d'État invite le gouvernement wallon à harmoniser la dénomination de l'une des sections du pôle « Ruralité »: «Tant dans la dénomination que dans la définition des missions et de la composition du pôle "Ruralité", section "Agriculture et Agro-alimentaire", l'auteur de l'avant-projet fait un usage des termes "Agriculture", "Agro-alimentaire" et "Alimentation" qui prête à confusion. En effet, alors que l'article $2 / 6, \S 1^{\mathrm{er}}, 1^{\circ}, \mathrm{f}$ ), et $4^{\circ}$, en projet fait expressément référence à ces trois notions lorsqu'il définit les missions du "pôle", l'article $2 / 6, \$ 7$, en projet vise uniquement les dossiers "relatifs à l'agriculture" et la dénomination de la nouvelle section ne fait plus référence à la notion d'“Alimentation" ». 


\subsubsection{Les débats autour des projets de décret}

L'adoption des avant-projets de décret par le gouvernement wallon en troisième lecture permet le dépôt des deux textes au Parlement wallon sous la forme de projets de décret au début du mois d'octobre $2016^{102}$. La Commission des Affaires générales et des Relations internationales est chargée d'examiner le dossier, auquel elle consacre quatre de ses séances ( 21 et 24 novembre 2016, 8 décembre 2016 et 16 janvier 2017) ${ }^{103}$. Les débats entre membres de cette commission et les réactions des différents acteurs mobilisés étant thématiquement liés, c'est de la sorte que ces éléments sont présentés ici.

En novembre et décembre 2016, la commission parlementaire procède à l'audition de divers experts : le secrétaire général du CESW (Jean-Pierre Dawance), des représentants d'organisations de la société civile (IEW, ConcertES, FPNW, etc.) ou des pouvoirs locaux (UVCW), des représentants du Conseil économique, social et environnemental (CESE) français, et des chercheurs académiques.

Par ailleurs, les cas du CESE français et du Conseil économique et social européen (CESE) ont fait l'objet d'une après-midi d'étude intitulée « Comment organiser le dialogue avec la société civile ? ", organisée à Namur le 17 octobre 2016 à l'initiative de ConcertES et d'IEW. L'objectif a été de présenter ces deux organes comme des exemples de «structures faîtières élargies » et d'en démontrer la plus-value. D'une part, le CESE français s'est ouvert à un pilier environnemental. En outre, son assemblée générale compte des représentants du secteur associatif au sens large. D'autre part, le CESE européen est composé, en plus du groupe « employeurs » et du groupe « travailleurs », d'un troisième groupe appelé «intérêts divers" rassemblant toute une série d'organisations de la société civile. Les acteurs wallons en faveur d'un élargissement de la structure faîtière ont défendu leur point de vue en argumentant que, si le CESW devient un outil de transmission des avis des pôles, avec possibilité d'intervention sur ceux-ci, il est souhaitable que la société civile soit représentée au sein de son bureau, d'autant que les interlocuteurs sociaux seront représentés dans les différents pôles (comme c'était le cas dans les conseils consultatifs). Une telle discussion a également lieu à plusieurs reprises au sein de la Commission des Affaires générales et des Relations internationales du Parlement wallon.

Réagissant à ce sujet, les interlocuteurs sociaux rappellent que, en ce qui concerne les changements structurels plus importants, ils ont eux-mêmes estimé qu'il était nécessaire d'ouvrir les discussions à d'autres acteurs de la société civile, notamment dans les cas où une maitrise technique particulière est nécessaire. En revanche, un tel apport n'a pas été jugé utile dans les domaines pour lesquels les interlocuteurs sociaux ont l'expertise requise, comme dans le cas, par exemple, des commissions internes au CESW suivantes, pour lesquelles les interlocuteurs sociaux souhaitent qu'elles demeurent au sein de la nouvelle structure faîtière: Action-Intégration sociale-Services collectifs-Santé (AIS), Économie-Politiques industrielles (EPI), Emploi-Formation-Éducation (EFE) et Finance-

102 Parlement wallon, Projet de décret modifiant le décret du 6 novembre 2008 portant rationalisation de la fonction consultative et diverses dispositions relatives à la fonction consultative, $\mathrm{n}^{\circ} 601 / 1,4$ octobre 2016 ; Parlement wallon, Projet de décret modifiant le décret-cadre du 6 novembre 2008 portant rationalisation de la fonction consultative pour les matières réglées en vertu de l'article 138 de la Constitution et diverses dispositions relatives à la fonction consultative, $n^{\circ}$ 602/1, 4 octobre 2016.

03 Parlement wallon, Commission des Affaires générales et des Relations internationales, Compte rendu intégral, $\mathrm{n}^{\circ} 40, \mathrm{n}^{\circ} 49, \mathrm{n}^{\circ} 61$ et $^{\circ}$ 76, 21 novembre 2016, 24 novembre 2016, 8 décembre 2016 et 16 janvier 2017. 
Institutionnel-Simplification administrative (FIS) ${ }^{104}$. Les interlocuteurs sociaux soulignent que le but de la fonction consultative, à savoir l'aide à la prise de décision politique, doit rester central dans son organisation. Dès lors, à leurs yeux, le fait d'élargir la composition des instances centrales du CESW de façon excessive risquerait de porter préjudice à l'efficacité de celles-ci. Relativement à la représentation des usagers dans le futur pôle "Mobilité », les interlocuteurs sociaux se disent également sceptiques : selon eux, la fonction consultative doit fonctionner autour des corps intermédiaires, et ne pas être ouverte de la manière dont pourrait l'être une enquête publique. Dans sa note préparant la deuxième lecture des avant-projets de décret, le gouvernement wallon avait déjà répondu sur ce point, en argumentant que ces acteurs font bel et bien partie de la société civile et en estimant qu'une décision de ne pas les inclure dans les pôles adéquats constituerait un recul. La Commission des Affaires générales et des Relations internationales du Parlement wallon suit cette logique de raisonnement.

Divers aspects de la nouvelle structure sont également commentés par les différents acteurs lors des auditions menées en commission parlementaire. Certains intervenants regrettent la perte d'indépendance dans le chef des anciens conseils spécialisés, puisque ceux-ci se retrouvent désormais dans des pôles liés au bureau du CESW. Ce que les uns appellent le « codicille » pour affirmer que le bureau du CESW ne transformera pas les avis mais les complétera le cas échéant, les autres l'apparentent à une subordination des pôles à la structure faîtière (équivalente à un affaiblissement de l'autonomie dont les conseils spécialisés bénéficiaient auparavant). Les organisations représentées au sein des différents conseils spécialisés expriment leurs réticences : elles craignent que les avis dégagés au sein des futurs pôles (au sein desquels il pourra être difficile d'atteindre un consensus) perdent en influence auprès du gouvernement wallon, après leur traitement par les interlocuteurs sociaux au CESW. Interrogé à cet égard par la commission parlementaire, le gouvernement Magnette, en la personne de son ministre-président, précise que les futurs pôles disposeront dans tous les cas d'un droit d'initiative dans la remise d'avis et que, par ailleurs, le CESW conservera - conformément à son décret constitutif - une faculté de remettre un avis sur tout projet régional.

Outre la relation entre la structure faîtière et les pôles, l'organisation interne de ces derniers fait également l'objet de discussions. La simplification annoncée est remise en question par divers intervenants, notamment au vu du nombre de membres, parfois important, prévu dans certains pôles; cet élément laisse à penser aux détracteurs de la réforme que celle-ci procède d'une simple addition des structures existantes (pour former les pôles) plutôt que d'une refonte en profondeur de ces structures. Le futur pôle « Ruralité » est pris comme exemple. Son noyau dur comptera 17 membres pour représenter les interlocuteurs sociaux, les pouvoirs locaux et les associations environnementales, agricoles et forestières. Y seront adjoints, selon la thématique traitée, des membres additionnels représentant les sections suivantes : « Nature» (10 personnes), «Chasse» (18 personnes), «Pêche» (20 personnes), «Forêt et filière bois » (14 personnes), " Agriculture, agro-

104 Ils ont également préconisé (dès l'avis du CESW du 28 septembre 2015), d'une part, que la Commission spéciale germanophone reste elle aussi dans la coupe du CESW et, d'autre part, que les quatre autres commissions internes préexistant à la réforme soient dirigées vers les futurs pôles correspondant aux matières traitées, à savoir les Commission Conservation de la nature-Environnement-Ruralité-Agriculture (CERA), Commission Énergie, Commission Mobilité-Aménagement du territoire (MAT) et Commission Villes-Logement-Équipement-Sécurité (VLES). 
alimentaire et alimentation»(20 personnes). Avec un tel nombre de membres, les discussions et la formulation d'avis risquent d'être complexes, et l'unanimité difficile à atteindre, déforçant l'influence de l'avis et potentiellement son utilité pour le gouvernement wallon.

Certains députés membres de la commission parlementaire soulèvent également des questions au sujet de la représentation de mandataires publics au sein des nouvelles instances consultatives proposées. Ils notent que l'exclusion annoncée des représentants du gouvernement et de l'administration n'est pas complètement respectée. En effet, si les représentants du gouvernement sont bel et bien exclus de la composition des instances (ils peuvent simplement être présents sur invitation), tel n'est pas totalement le cas des représentants de l'administration, puisqu'ils sont présents dans certains pôles. Le CESW répond que la situation dépend du sens, large ou étroit, que l'on donne à "l'administration». Dans certains secteurs, les acteurs administratifs tels que les organismes d'intérêt public sont des acteurs à part entière, voire des acteurs exclusifs. Tel est le cas, par exemple, de la Société régionale wallonne du transport (SRWT) dans le futur pôle "Mobilité » et de la Société publique de gestion de l'eau (SPGE) dans la section «Eau» du futur pôle «Environnement». Dans ces cas-là, le pragmatisme l'emporte dans le respect du principe d'exclusion des représentants du gouvernement et de l'administration.

Les débats portent également sur la question des jetons de présence: par souci d'harmonisation entre les instances, la réforme propose de supprimer totalement ceux-ci (sauf mesures dérogatoires, par exemple en faveur d'architectes invités à siéger pour des dossiers portant sur des questions d'aménagement du territoire). Jusqu'alors, en fonction de l'histoire de chaque instance, les jetons existaient ou non et, là où ils étaient de mise, le rapport entre les montants variait de 1 à 10. D'après les représentants du CESW, il n'est pas établi qu'il existe une corrélation entre jetons de présence et absentéisme. La suppression des jetons de présence n'en est pas moins débattue en commission parlementaire. L'opposition estime qu'une suppression des jetons de présence présente le risque de décourager les bénévoles (Écolo) et souligne que les montants en jeu n'ont jamais été fort élevés. En réponse, la majorité argue que, pour la plupart des membres des instances consultatives, le fait de participer à la fonction consultative fait partie intégrante des tâches pour lesquelles ils sont déjà rémunérés par les organisations qui les emploient. Sauf exception, il n'y a donc pas de raison qu'ils reçoivent un émolument pour siéger dans l'une ou l'autre instance consultative.

À l'issue des débats en Commission des Affaires générales et des Relations internationales du Parlement wallon, les députés de la majorité, et particulièrement ceux du PS (les députés du $\mathrm{CDH}$ s'exprimant peu de manière tranchée), estiment que les décrets proposés traduisent bien la volonté de l'exécutif régional d'augmenter l'efficacité des processus de consultation en harmonisant et en recentrant les différentes instances autour du CESW ${ }^{105}$. À l'inverse, l'opposition exprime son scepticisme sur la réforme projetée. Pour Écolo, le gouvernement passe à côté de son ambition : il n'y a pas de changements fondamentaux, la réforme via la structuration en pôles s'apparentant à une juxtaposition des instances antérieures. Pour le MR, les objectifs annoncés de la réforme, à savoir la réduction

105 Parlement wallon, Commission des Affaires générales et des Relations internationales, Compte rendu intégral, $\mathrm{n}^{\circ} 76,16$ janvier 2017, p. 34. 
du nombre d'organes, la simplification du fonctionnement et l'amélioration de la représentativité démocratique des instances consultatives, ne sont pas atteints et le projet n'est donc pas satisfaisant en l'état.

Répondant à ceux qui considèrent que la réforme constitue une "magnifique occasion manquée ", notamment en ce qui concerne la représentation d'autres acteurs que les interlocuteurs sociaux dans la structure faîtière, le ministre-président, P. Magnette, indique : "Cette question a été débattue. (...) Les raisons pour lesquelles le choix a été fait de ne pas aller dans cette direction, c'est principalement pour deux raisons. Premièrement, c'est un débat qui est un débat éternel dans ces organes, c'est une question de représentativité. Qu'on les aime ou non, les représentations syndicales ont une représentativité claire (...) et c'est le cas aussi des organisations représentatives des employeurs. C'est moins le cas dans toute une autre série qui est organisée sur des bases ad hoc qui ne représentent pas forcément des membres de manière aussi massive (...). C'est un vieux débat, mais c'est un débat qui reste aujourd'hui pertinent. Si l'on veut que cette instance [le CESW] qui a sa légitimité socio-économique parce qu'elle représente des intérêts socio-économiques organisés, structurés, avec des statuts, et cetera, ait une légitimité, il faut que les membres qui la composent aient eux-mêmes ce type de légitimité. La deuxième raison, c'est que "qui trop embrasse, mal étreint" et qu'à vouloir trop élargir ce type d'organes, on finit souvent par les diluer. C'est déjà très difficile d'arriver à faire en sorte qu'un organe comme le CESW parvienne à créer une vraie culture de la consultation dans laquelle [sont donnés] de vrais avis au gouvernement ${ }^{106}$.

\subsubsection{L'adoption des décrets}

La Commission des Affaires générales et des Relations internationales adopte les deux projets de décret le 16 janvier 2017. Les deux textes sont alors discutés en séance plénière du Parlement wallon le 15 février $2017^{107}$. Ce jour-là, après un débat, 72 députés prennent part au vote relatif au décret portant rationalisation de la fonction consultative pour les matières régionales wallonnes ; 43 députés (issus de la majorité PS/CDH) votent en faveur du décret, 5 se prononcent contre (les députés Écolo et le député indépendant Pierre-André Puget) et 24 s'abstiennent (issus des rangs du MR et du PTB). Pour sa part, le second décret, portant rationalisation de la fonction consultative pour les matières dont l'exercice a été transféré à la Région wallonne par la Communauté française, est adopté dans les mêmes proportions, seuls deux députés ayant exclusivement ou en premier lieu prêté serment en langue allemande ne pouvant pas participer au vote (puisqu'il s'agit de matières communautaires, conformément à l'article 50, alinéa 2, de la loi spéciale de réformes institutionnelles du 8 août 1980).

Datés du lendemain, les deux décrets entrent en vigueur le 4 juillet 2017, c'est-à-dire 90 jours après le 5 avril 2017, date de leur publication au Moniteur belge ${ }^{108}$.

106 Ibidem, p. 34.

107 Parlement wallon, Compte rendu intégral, n 14, 15 février 2017.

108 Décret wallon du 16 février 2017 modifiant le décret du 8 novembre 2008 portant rationalisation de la fonction consultative et diverses dispositions relatives à la fonction consultative, Moniteur belge, 5 avril 2017 (et erratum: Moniteur belge, 4 mai 2017) ; Décret wallon du 16 février 2017 modifiant le décret-cadre du 8 novembre 2008 portant rationalisation de la fonction consultative pour les matières 


\subsection{LES SUITES DE LA RÉFORME}

D'une part, cette dernière section résume les points essentiels de la réforme de l'architecture de la fonction consultative wallonne. D'autre part, elle présente les étapes ultérieures à l'adoption des décrets, visant à l'installation effective de la nouvelle mouture de cette fonction consultative. Dans ce cadre, elle évoque notamment les propositions touchant à la fonction consultative émanant du gouvernement Borsus (MR/CDH), installé le 28 juillet 2017 en remplacement du gouvernement Magnette (PS/CDH).

\subsubsection{L'architecture de la fonction consultative réformée}

Au niveau décrétal, l'approbation de la réforme a consisté en l'adoption de deux décrets modifiant les décrets du 6 novembre 2008. Dans une première partie, les décrets modifiés listent toutes les nouvelles instances créées ${ }^{109}$. Ensuite, un nouveau chapitre $1^{\mathrm{er}} / 1$ intitulé «De l'organisation de la fonction consultative en pôles, de leurs missions et de leurs compositions » est intégré dans le décret. Ce chapitre assigne la mission de fonction consultative aux pôles et définit celle-ci (cf. supra). Il expose également les missions, la composition et les modalités générales de fonctionnement de chacun des sept pôles. Il détaille aussi les modifications décrétales à effectuer au vu de l'impact de la réforme.

La nouvelle architecture de la fonction consultative s'organise de la manière suivante (ci-après, les instances dont le nom est suivi d'un astérisque sont celles qui concernent des matières dont l'exercice a été transféré de la Communauté française à la Région wallonne).

Primo, le CESW comprend cinq «commissions internes» (au lieu de neuf précédemment ${ }^{110}$ ):

- Commission de l'Économie, des Investissements, des Politiques industrielles et sectorielles, du Tourisme et du Commerce extérieur;

- Commission de l'Emploi, de la Formation et de l'Éducation ;

- Commission de l'Action et de l'Intégration sociale, des Services collectifs et de la Santé (élargie le cas échéant à l’une de ses deux sections ${ }^{111}$ : «Action sociale » ${ }^{112}$

réglées en vertu de l'article 138 de la Constitution et diverses dispositions relatives à la fonction consultative, Moniteur belge, 5 avril 2017.

109 Les instances préservées et conservées au sein de la fonction consultative générique sont également énumérées, car elles sont concernées par les mesures transversales contenues dans le décret.

110 Les commissions internes au CESW dont les thématiques sont dorénavant prises en charge par les pôles cessent donc de fonctionner. Néanmoins, elles ne sont pas formellement supprimées puisqu'elles ne disposent pas, à la base, d'une existence légale et sont le fruit de l'organisation interne du CESW.

111 La fonction consultative relative à ces deux sections était jusqu'alors assurée par les deux commissions du Conseil wallon de l'action sociale et de la santé (CWASS). La désignation des experts associés à ces deux sections sera effectuée par décision de l'assemblée générale du CESW le 15 janvier 2018, suite à l'appel à candidatures paru au Moniteur belge le 17 octobre 2017.

112 La section "Action sociale » est composée de 10 membres issus des instances ou des organisations suivantes : l'UVCW, la Fédération des CPAS, le Réseau wallon de lutte contre la pauvreté (RWLP), les organisations actives en matière d'accueil et hébergement, le centre de référence agréé ou les services de médiation de dettes agréés ou l'Observatoire du crédit et de l'endettement (OCE), les services d'aide et de soins aux personnes prostituées, les organisations actives en matière d'insertion sociale, et les centres de services sociaux. 
et « Intégration des personnes étrangères ou d’origine étrangère » ${ }^{113}$, pour les matières qui les concernent $\left.{ }^{114}\right)$;

- Commission Finances (Budget, Fiscalité), Institutionnel, Europe, Simplification administrative ;

- Commission spéciale germanophone.

Secundo, les anciennes instances de la consultation dite générique sont dorénavant principalement réparties en sept pôles thématiques ${ }^{115}$. Ceux-ci sont logés auprès du CESW, qui en assure le secrétariat et qui est conforté dans sa place d'acteur central de l'organisation de la fonction consultative. L'assemblée générale du CESW et son bureau restent inchangés au niveau des organisations qui les composent. Le tableau 1 liste les pôles, en précisant, d'une part, leurs éventuelles sections et, d'autre part, les anciennes instances consultatives correspondantes (qui cessent donc d'exister sous leur ancienne forme ou dénomination et sont donc remplacées, dans les différents décrets où il en était fait mention, par les différents pôles). Comme présenté à la suite du tableau 1, certaines instances sont maintenues en l'état au sein du CESW, tandis que d'autres sont transférées vers l'administration (le Service public de Wallonie - SPW) ou vers des organismes d'intérêt public.

Tableau 1. Pôles thématiques du CESW (réforme de 2017)

Pôles

Anciennes instances consultatives

\begin{tabular}{|l|l|}
\hline Pôle « Politique scientifique » & $\begin{array}{l}\text { - Conseil de la politique scientifique (CPS) } \\
\text { - Conseil wallon de l'évaluation, de la prospective } \\
\text { et de la statistique (CWEPS) }\end{array}$ \\
\hline Pôle « Mobilité » & $\begin{array}{l}\text { - Conseil de la mobilité } \\
\text { - Commission du transport et de la mobilité } \\
\text { - Comité consultatif des transports publics de personnes } \\
\text { par route }\end{array}$ \\
\hline
\end{tabular}

113 La section «Intégration des personnes étrangères ou d'origine étrangère » est composée de 10 membres issus des instances ou des organisations suivantes : l'UVCW, la Fédération des CPAS, les organisations actives en matière d'intégration des personnes étrangères ou d'origine étrangère, et les centres régionaux d'intégration.

114 La composition de ces deux sections varie en fonction des sujets traités ; elle est déterminée par le CESW afin d'assurer une représentativité adéquate des secteurs concernés selon la thématique. Le CESW invite les autorités, les associations ou les organismes représentés au sein des sections à lui soumettre les candidatures qui lui paraissent représentatives.

115 Leur composition figure dans l'annexe du présent Courrier hebdomadaire.

116 Le Conseil de la mobilité correspondait à l'une des actions en matière de gouvernance préconisée par le Schéma régional de mobilité (SRM). Celui-ci était un document non officiel présenté en janvier 2016 au cabinet du ministre wallon en charge de la Mobilité, C. Di Antonio, après consultation d'une septantaine de parties prenantes; il n'a pas été approuvé par le gouvernement Magnette avant son remplacement par le gouvernement Borsus. Le Conseil de la mobilité n'avait donc pas encore été institué en date de l'adoption de la réforme de la fonction consultative wallonne, bien qu'il en ait été tenu compte dans le cadre de cette réforme.

117 La Commission du transport et de la mobilité était une instance dépendante de la Direction générale opérationnelle des Routes et des Bâtiments (DGO1), mais elle n'avait jamais été effectivement mise en place.

118 Le Comité consultatif des transports publics de personnes par route était une instance dépendante de la Direction générale opérationnelle des Routes et des Bâtiments (DGO1), mais elle n'avait jamais été effectivement mise en place. 


\begin{tabular}{|c|c|}
\hline Pôle « Énergie » & $\begin{array}{l}\text { - Conseil général de l'énergie } \\
\text { - Conseil général de la Commission wallonne pour l'énergie }\end{array}$ \\
\hline Pôle « Logement » & - Conseil supérieur du logement (CSL) \\
\hline $\begin{array}{l}\text { Pôle « Aménagement du territoire » } \\
\text { (Deux sections : «Aménagement régional » } \\
\text { et « Aménagement opérationnel ») }\end{array}$ & - Commission régionale d'aménagement du territoire (CRAT) \\
\hline $\begin{array}{l}\text { Pôle « Environnement» } \\
\text { (Trois sections : «Eau », « Déchets » et « Sols ») }\end{array}$ & $\begin{array}{l}\text { - Conseil wallon de l'environnement pour le développement } \\
\text { durable (CWEDD) } \\
\text { - Commission consultative de l'eau (CCE) } \\
\text { - Commission des déchets (CDD) }\end{array}$ \\
\hline $\begin{array}{l}\text { Pôle « Ruralité » } \\
\text { (Cinq sections : « Nature », « Chasse », } \\
\text { "Pêche », «Forêt et filière bois » et « Agriculture, } \\
\text { agro-alimentaire et alimentation ») }\end{array}$ & $\begin{array}{l}\text { - Conseil supérieur wallon de l'agriculture, de l'agro-alimentaire } \\
\text { et de l'alimentation (CSWAAA) } \\
\text { - Commission consultative scientifique pour les produits } \\
\text { agro-alimentaires (CCSPA) } \\
\text { - Conseil supérieur wallon de la conservation de la nature } \\
\text { (CSWCN) } \\
\text { - Conseil supérieur wallon de la chasse (CSWC) } \\
\text { - Conseil supérieur wallon de la pêche (CSWP) } \\
\text { - Conseil supérieur wallon des forêts et de la filière bois } \\
\text { (CSWFBB) }\end{array}$ \\
\hline
\end{tabular}

Tertio, il existe six « conseils consultatifs ». Trop spécifiques pour être intégrées à des pôles, ces instances ont été maintenues en l'état. Elles restent logées au CESW, qui en assure le secrétariat:

- Commission royale des monuments, sites et fouilles de la Région wallonne (CRMSF) ;

- Conseil supérieur du tourisme ;

- Conseil wallon de l'économie sociale (CWES);

- Conseil wallon de l'égalité entre hommes et femmes (CWEHF) *

- Comité de contrôle de l'eau (CContrEau);

- Observatoire du commerce.

Quarto, huit «commissions d'agrément » restent gérées par le CESW, en raison des matières qu'elles traitent, à savoir des matières liées à l'emploi et à la formation ${ }^{120}$ :

- Commission consultative et de concertation en matière de placement (COPLA) ${ }^{121}$;

119 Ce Conseil général était, comme son nom l'indique, lié à la Commission wallonne pour l'énergie (CWAPE), qui est l'instance régionale de régulation des marchés de l'électricité et du gaz. Il n'avait jamais été effectivement activé.

120 Quant à lui, le Comité d'orientation en matière d'accompagnement des reconversions a été supprimé. Une mission d'avis générale portant sur les reconversions a été confiée au CESW, qui l'exercera probablement à travers les travaux de sa Commission de l'Emploi, de la Formation et de l'Éducation.

${ }^{121}$ Le placement est une matière exclusivement régionale (cf. le décret wallon du 3 avril 2009 relatif à l'enregistrement ou à l'agrément des agences de placement, Moniteur belge, 5 mai 2009), mais il est inscrit dans les deux décrets wallons relatifs à la fonction consultative (en raison d'une erreur historique commise lors de l'adoption de ces décrets en 2008 et non corrigée lors de la réforme opérée en 2017). 
- Commission consultative et d'agrément des entreprises d'économie sociale (COMES) ;

- Commission Chèques (agrément des opérateurs de formation en matière de chèques-formation) * ;

- Commission CISP (agrément à destination des centres d'insertion socioprofessionnelle - CISP) *;

- Commission PMTIC (agrément à destination des organismes de formation relevant du Plan mobilisateur des technologies de l'information et de la communication - PMTIC) ${ }^{\star}$;

- Commission Congé-éducation payé ;

- Commission consultative d'agréments des entreprises titres-services;

- Commission consultative Fonds de formation titres-services.

Quinto, certaines instances sont déplacées vers le SPW (ce qui entraîne des mouvements de personnel ${ }^{122)}$ :

- la Commission d'agrément des auteurs de projets (CAAP) : vers la Direction générale opérationnelle de l'Aménagement du territoire, du Logement, du Patrimoine et de l'Énergie (DGO4);

- la Commission d'avis sur les recours en matière d'urbanisme (CAR) : également vers la DGO4;

- les 8 commissions de conservation des sites Natura 2000: vers la Direction générale opérationnelle Agriculture, Ressources naturelles et Environnement (DGO3) ;

- la Commission régionale d'avis pour l'exploitation des carrières (CRAEC) : à confirmer ${ }^{123}$;

- la Commission Formation agricole ${ }^{\star 124}$.

Sexto, le Conseil supérieur du tourisme emprunte quant à lui le chemin inverse, puisqu'il est transféré du Commissariat général au tourisme (CGT, qui est le nom de l'administration wallonne en charge du tourisme) vers le CESW, entraînant une modification de sa composition pour y inclure des représentants des interlocuteurs sociaux.

Septimo, d'autres instances sont transférées vers des organismes d'intérêt public:

- le Conseil consultatif de la formation en alternance $(\mathrm{CCFA})^{*}$ : vers l'Office francophone de la formation en alternance (OFFA);

${ }^{122}$ Le décret précise que les membres du personnel du CESW peuvent être transférés sur une base volontaire au SPW (et vice-versa) selon les modalités déterminées par le gouvernement (cf. l'article $2 / 1, \$ 2$, al. 5 et 6 , du décret wallon du 6 novembre 2008 modifié par le décret du 16 février 2017 portant rationalisation de la fonction consultative et diverses dispositions relatives à la fonction consultative). Cf. aussi l'arrêté du gouvernement wallon du 29 juin 2017 relatif aux modalités de transfert du personnel dans le cadre de la réforme de la fonction consultative (Moniteur belge, 5 septembre 2017).

${ }^{123}$ Ce transfert était mentionné dans la note du gouvernement, mais il n'en est question ni dans le décret ni dans l'arrêté d'exécution.

124 La Commission Formation agricole existe toujours selon les textes, cependant son budget a été supprimé et son secrétariat transféré à l'administration. Dans les faits, elle ne fonctionne plus. 
- le Comité d'experts chargés de l'examen des demandes d'agrément de systèmes d'épuration individuelle : vers la Société publique de gestion de l'eau (SPGE);

- les commissions Santé *, Famille *, Aînés * et Personnes handicapées ${ }^{* 125}$ du Conseil wallon de l'action sociale et de la santé (CWASS) ${ }^{126}$ : vers le Conseil de stratégie et de prospective de l'Agence wallonne pour une vie de qualité (AVIQ).

Octavo et enfin, en ce qui concerne la fonction consultative des pouvoirs locaux, le Conseil supérieur des villes, communes et provinces de la Région wallonne (CSVCP) - dont le secrétariat était assuré par le SPW - est supprimé. Dorénavant, le gouvernement wallon consultera de manière bilatérale l'Union des villes et communes de Wallonie (UVCW), la Fédération des CPAS et l'Association des provinces wallonnes (APW).

Un principe de neutralité budgétaire s'applique pour la réforme. Le changement provient du type de dotation octroyé au CESW. Jusqu'à présent, le CESW gérait et disposait de diverses subventions octroyées par différents départements administratifs et différents ministres pour le financement partiel de certaines instances dont il assure le secrétariat (cf. supra). Dorénavant, dans un souci de simplification administrative et de gestion budgétaire, une dotation unique est mise en place pour le CESW et les pôles. Représentant quelque 5292000 euros (pour le budget 2018), elle émarge au budget du ministreprésident. Il revient au CESW d'allouer leurs ressources respectives aux pôles.

\subsubsection{Les débuts de la mise en place de la réforme}

La réforme s'est concentrée sur les instances consultatives qualifiées de génériques (c'est-à-dire, pour rappel, des organes dont la mission principale consiste à remettre des avis au gouvernement ou au Parlement sur des notes d'orientation du gouvernement, des textes à portée générale ou des avant-projets de décret ou d'arrêté à portée réglementaire). Interpellé à plusieurs reprises au Parlement sur la portée limitée de la réforme - compte tenu des dizaines d'autres organes, qualifiés de techniques, laissés intacts dans leur nombre et leur complexité (mis à part le renvoi vers l'administration) -, le ministre-président P. Magnette a indiqué dès le mois de décembre 2015 que le gouvernement wallon continuerait son travail de réforme, "notamment à l'initiative des différents ministres fonctionnels » compétents pour les différentes matières traitées par les instances consultatives techniques ${ }^{127}$.

125 Quant à elle, la commission d'avis sur les recours en matière d'action sociale et de santé * du CWASS reste logée au sein de la Direction générale opérationnelle des Pouvoirs locaux et de l'Action sociale (DGO5).

126 Le CWASS est donc en passe d'être supprimé, puisque ses sept commissions (cf. aussi les notes 111 et 125) sont désormais relogées dans d'autres instances. Toutefois, sa suppression n'est pas encore officielle, car une disposition transitoire du décret créant l'AVIQ prévoit que, tant que celle-ci n'a pas mis sur pied ses propres organes consultatifs, les structures précédentes continuent à exister. Hormis le caractère exceptionnel lié à la création de l'AVIQ, cela correspond à la logique générale de la mise en ouvre de la réforme : outre d'adopter les décrets réformant la fonction consultative, il convient de procéder à la modification de l'ensemble des décrets faisant mention, instituant ou définissant les instances qui sont transformées par la nouvelle architecture. Ces instances cessent d'exister sous cette forme, mais elles continuent d'exister dans leurs missions qui sont transférées au sein des nouveaux pôles ou autres (cf. supra). Parlement wallon, Compte rendu intégral, n 63, 4 décembre 2015, p. 16. 
En raison de son aspect résolument transversal, la réforme adoptée en 2017 requiert une mise en œuvre conséquente. Dès le 9 février 2017, le gouvernement wallon Magnette adopte en première lecture les avant-projets d'arrêté portant exécution des futurs décrets du 16 février 2017 et sollicite l'avis du CESW sur ceux-ci. L'objectif principal de ces avantprojets d'arrêté d'exécution « consiste à supprimer de la littérature juridique les textes réglementaires qui n'ont plus lieu d'être ou de les adapter de sorte à y exprimer les nouvelles terminologies » ${ }^{128}$. Le 3 avril 2017, le CESW remet un avis ${ }^{129}$ contenant des recommandations relatives aux projets d'arrêté, en vue de garantir la bonne application des décrets adoptés et l'opérationnalisation des nouvelles structures. Certaines précisions concernant l'instauration des pôles y sont réclamées. Par exemple, concernant le mandat germanophone au sein des sections "Forêt et filière bois" et "Agriculture, agroalimentaire et alimentation » du pôle "Ruralité », il s'agit de déterminer quels doivent être les critères utilisés pour la sélection du représentant (domicile, lien institutionnel, connaissance spécifique). Le Conseil d'État avait d'ailleurs demandé, dans son avis rendu le 18 juillet 2016 concernant le projet de décret relatif à la réforme de la fonction consultative pour les matières régionales, une justification dans l'exposé des motifs sur la présence d'un membre germanophone dans certaines sections du pôle "Ruralité » et pas dans les autres sections de ce pôle ni dans les autres pôles. L'avis du CESW constitue également l'occasion de recommander au gouvernement de prévoir des mesures transitoires en attendant la mise sur pied de l'ensemble des nouveaux pôles créés.

Le gouvernement wallon suit les recommandations du CESW en lien avec les textes réglementaires concernés. Il adopte les avant-projets d'arrêté en deuxième lecture le 11 mai 2017, puis les transfère pour avis au Conseil d'État. Celui-ci remet une note d'observations ${ }^{130}$, à titre indicatif et sans portée normative, contenant des observations de type légistique qui sont également intégrées par le gouvernement aux avant-projets d'arrêté.

Les deux arrêtés sont finalement adoptés par le gouvernement Magnette le 29 juin $2017^{131}$. Un troisième arrêté est par ailleurs également adopté le même jour, concernant les transferts de personnel ${ }^{132}$.

Les transferts d'instances et de personnel et l'installation des nouvelles instances s'opèrent de manière progressive. Le CESW sollicite les services d'une société de consultance pour une mission d'accompagnement et de communication du changement.

La composition des pôles est déterminée sur la base d'appels à candidatures publiés au Moniteur belge - méthode préconisée par le Conseil d'État dans son avis du 18 juillet 2016. Les différents membres seront nommés par le gouvernement wallon. À l'heure de publier

128

Cabinet du ministre-président P. Magnette, Note au gouvernement wallon, 29 juin 2017.

CESW, Avis n A.1335, 3 avril 2017.

${ }_{130}$ Bureau de coordination du Conseil d'État, Note d'observations (à titre indicatif), 7 juin 2017.

Arrêté du gouvernement wallon du 29 juin 2017 modifiant divers arrêtés en vue d'exécuter le décret du 16 février 2017 modifiant le décret du 6 novembre 2008 portant rationalisation de la fonction consultative et modifiant diverses dispositions relatives à la fonction consultative, Moniteur belge, 5 septembre 2017 ; Arrêté du gouvernement wallon du 29 juin 2017 modifiant divers arrêtés en vue d'exécuter le décret du 16 février 2017 modifiant le décret-cadre du 6 novembre 2008 portant rationalisation de la fonction consultative pour les matières réglées en vertu de l'article 138 de la Constitution et modifiant diverses dispositions relatives à la fonction consultative, Moniteur belge, 5 septembre 2017.

Arrêté du gouvernement wallon du 29 juin 2017 relatif aux modalités de transfert du personnel dans le cadre de la réforme de la fonction consultative, Moniteur belge, 5 septembre 2017. 
ces lignes, la composition de six des sept pôles a déjà été arrêtée ${ }^{133}$ : le pôle «Environnement» le 25 août $2017^{134}$, le pôle «Énergie» le 27 novembre $2017^{135}$, le pôle « Aménagement du territoire » le 21 décembre $2017^{136}$, le pôle « Ruralité » le 15 janvier $2018^{137}$, le pôle « Politique scientifique » le 2 février $2018^{138}$ et le pôle «Logement» le 20 février $20188^{139}$. Depuis l'été 2017, les pôles sont donc graduellement mis en place, selon une chronologie propre à chacun d'eux (les appels à candidatures n'ayant pas tous été lancés au même moment).

Tant qu'un pôle n'est pas mis en place, les anciennes instances consultatives qu'il est amené à remplacer continuent de fonctionner. Lorsqu'un pôle est constitué, l'une de ses premières tâches consiste à adopter son règlement d'ordre intérieur, dans la lignée des principes généraux de la réforme. Cela constitue, d'une part, une étape importante, au vu de l'autonomie que les principes transversaux de la réforme laissent aux pôles en termes d'organisation spécifique et, d'autre part, un défi d'harmonisation, car l'ambition est de pouvoir doter tous les organismes consultatifs logés au sein du CESW (c'est-à-dire les pôles, mais également les différents comités, commissions, conseils et observatoire) de bases aussi communes que possible. Actuellement, les règlements d'ordre intérieur sont toujours en cours d'élaboration. Le CESW, via les secrétariats des différents organismes consultatifs, se charge de coordonner la rédaction de ces documents. Les points à accorder touchent aux procédures de désignation des différentes catégories de membres, à l'organisation des réunions, aux modalités pratiques de formulation et de remise d'avis (par exemple, l'invitation d'experts ou les quorums de présence), à la gestion financière (consistant essentiellement dans le remboursement des frais des membres, puisque le décret supprime les jetons de présence), etc.

Un travail est également effectué au sein du CESW en ce qui concerne les dynamiques de travail entre les pôles et le bureau du CESW, puisque ce dernier devient le canal unique des demandes et des remises d'avis provenant des ministres fonctionnels. Le 9 octobre 2017, lors d'une réunion du bureau, les interlocuteurs sociaux ont proposé que le CESW ne remette pas d'avis complémentaire à celui d'un pôle dans le cas où il y a eu unanimité au sein dudit pôle. Cette prise de position constitue un point nouveau dans le débat précédemment évoqué au sujet du pouvoir - critiqué par certains acteurs - du CESW d'ajouter des compléments aux avis formulés par les pôles. Cela s'inscrit dans l'esprit des décrets finalement adoptés, qui confirment le rôle de secrétariat du CESW pour les pôles mais pas son caractère « faîtier » par rapport au contenu des avis remis par ceux-ci.

Une série d'aspects relatifs à la mise en ouvre de la réforme de la fonction consultative est donc toujours en cours au moment de la publication du présent Courrier hebdomadaire.

133 Pour chaque pôle, après clôture de l'appel à candidatures, la désignation des membres (« composition du pôle ») fait l'objet d'un arrêté du gouvernement wallon puis d'une publication au Moniteur belge. Les dates mentionnées ici font référence à ce que le CESW appelle l'« installation » d'un pôle, qui a lieu après la publication de la composition au Moniteur belge (à l'exception du pôle "Environnement », qui a débuté ses activités avant cette publication officielle) et qui correspond à la mise en route des activités de demandes et remises d'avis via la nouvelle structure.

134 Arrêté du gouvernement wallon du 17 août 2017 (Moniteur belge, 21 septembre 2017).

Arrêté du gouvernement wallon du 21 septembre 2017 (Moniteur belge, 17 octobre 2017).

136 Arrêté du gouvernement wallon du 26 octobre 2017 (Moniteur belge, 16 novembre 2017).

${ }_{137}$ Arrêté du gouvernement wallon du 28 septembre 2017 (Moniteur belge, 12 octobre 2017).

${ }_{138}$ Arrêté du gouvernement wallon du 21 décembre 2017 (Moniteur belge, 12 janvier 2018).

139 Arrêté du gouvernement wallon du 21 décembre 2017 (Moniteur belge, 12 janvier 2018). 
Le rapport d'activités 2016 du CESW annonce que la nouvelle structure de la fonction consultative et celle de ses composantes seront présentées et détaillées dans le rapport d'activités $2017^{140}$.

Par ailleurs, les rebondissements de la vie politique wallonne durant les mois de juin et juillet 2017, avec le remplacement du gouvernement Magnette (PS/CDH) par le gouvernement Borsus (MR/CDH) le 28 juillet 2017, ont touché à la fonction consultative, au-delà de la réforme récemment adoptée. En effet, la déclaration de politique régionale du gouvernement Borsus annonce une modification de la structure du CESW pour y introduire un pilier environnemental : "Compte tenu de l'évolution de la société et de l'importance des enjeux climatiques et du développement durable, et à l'instar des réformes initiées en France, la concertation sociale sera renforcée en ouvrant la porte $\mathrm{du}[\mathrm{CESW}]$ et des instances de concertation aux acteurs environnementaux $»{ }^{141}$. Cette déclaration a le potentiel de modifier substantiellement l'architecture institutionnelle et organisationnelle de la fonction consultative et de relancer les débats quant à la représentativité des différents acteurs impliqués à ses différents niveaux. Elle n'a néanmoins, à l'heure actuelle, été suivie d'aucune action politique de la part du gouvernement Borsus en ce sens. De plus, les interlocuteurs sociaux, via le CESW, affirment vouloir finaliser la mise en place de la réforme actuelle et procéder à une première évaluation avant d'envisager une nouvelle réforme.

140 Ce document devrait paraître vers avril-mai 2018.

${ }^{141}$ Gouvernement wallon, « La Wallonie plus forte », Déclaration de politique régionale, 25 juillet 2017, p. 7. 


\section{CONCLUSION}

La présentation sur le temps long de la fonction consultative wallonne, avec un focus sur ses dernières transformations, a permis de mettre en lumière plusieurs de ses éléments caractéristiques. Primo, l'institutionnalisation des structures offre aux instances consultatives une place officielle dans le paysage politique wallon. Secundo, cette institutionnalisation convoque des impératifs de représentativité dans le chef des organes et organisations membres de ces instances. Historiquement, ce sont les interlocuteurs sociaux qui détiennent le monopole de la représentativité et disposent d'une légitimité assurée en raison de leur professionnalisation. Tertio, la prise en charge de matières de plus en plus variées élargit cependant le spectre de la fonction consultative ainsi que la composition des instances aux organisations de la société civile. En ce sens, les procédures de rationalisation semblent inhérentes au développement de la fonction consultative.

La dernière réforme de la fonction consultative est marquée par ces caractéristiques. Elle a été guidée par trois objectifs : la réduction du nombre d'instances, la simplification de leur fonctionnement, l'amélioration de leur représentativité démocratique. Elle a mené à une refonte de l'architecture du CESW, qui héberge maintenant, outre ses commissions internes centrées sur les matières économiques et sociales, des pôles thématiques (au nombre de sept) intégrant d'anciennes instances, tout en maintenant intacts ses organes centraux - bureau et assemblée générale. Le caractère limité de la réforme par rapport au nombre d'instances consultatives recensées en début du processus, ainsi que le maintien du monopole des acteurs historiques de la consultation, à savoir les interlocuteurs sociaux, ont conduit certains acteurs - députés wallons ou organisations de la société civile à remettre en cause le principe de «table rase » de la fonction consultative évoqué par le ministre-président Paul Magnette au début du processus d'élaboration de la réforme.

La fonction consultative wallonne, de par son rôle de conseil à la prise de décision politique, est constamment appelée à prendre en compte les évolutions politiques, institutionnelles et sociétales de la Wallonie. Récemment encore, le changement survenu à la tête de la Région wallonne le 28 juillet 2017, lorsque le gouvernement Borsus $(\mathrm{MR} / \mathrm{CDH})$ a succédé au gouvernement Magnette (PS/CDH), a donné lieu à une nouvelle déclaration de politique régionale. Dans sa partie relative à la fonction consultative, cette déclaration prône un élargissement des instances du CESW au pilier environnemental. Une telle transformation, si elle a lieu, reviendrait à élargir la composition des organes internes du CESW (assemblée générale, bureau et commissions internes) en modifiant le décret constitutif du 25 mai 1983. Dans cette hypothèse, il reste à savoir quelle(s) mission(s) du CESW cela concernerait et si cette annonce est susceptible de remettre en question l'équilibre paritaire sur lequel repose historiquement le système de concertation belge auquel se rattache la fonction consultative. 
Observer les transformations de la fonction consultative invite également à questionner son rôle dans le processus de décision politique. La réforme étudiée dans la présente livraison du Courrier hebdomadaire porte essentiellement sur l'architecture interne de la fonction consultative. Sur le plan plus externe des échanges entre les instances consultatives et les décideurs politiques, seuls deux changements semblent notoires: d'une part, la volonté de supprimer les sièges dévolus aux représentants du gouvernement dans les instances consultatives et, d'autre part, la création ${ }^{142}$ de la saisine parlementaire ${ }^{143}$. En dehors de cela, les décrets réformés et les discussions autour de leur nature n'évoquent pas l'implication du travail consultatif dans la prise de décision politique, à savoir la question du traitement que le gouvernement wallon réserve aux avis des instances consultatives. Or la volonté d'améliorer l'efficacité de la fonction consultative en réorganisant le fonctionnement des instances ne prendra pleinement sens que si la fonction consultative est considérée dans le cadre plus large de la prise de décision politique en Wallonie. L'un des objectifs annoncés de la réforme de la fonction consultative est l'amélioration de la représentativité démocratique. Cette question a été débattue eu égard à la composition des instances, en particulier des pôles et des organes internes du CESW. Elle a en revanche été relativement peu évoquée sous l'angle de la participation d'acteurs non élus à l'élaboration des politiques, alors même que les institutions politiques wallonnes ne sont pas épargnées par la crise de la démocratie représentative. Réfléchir à des articulations entre cette problématique et l'instrument consultatif témoignerait du souci d'un véritable échange démocratique entre les acteurs consultés et les décideurs politiques traditionnels.

142 Il faudra voir à l'usage la manière dont le Parlement wallon se servira de la nouvelle possibilité de saisine qui lui est octroyée. Pour rappel, cette assemblée avait jusqu'alors la possibilité d'interroger directement le CESW (donc sans passer par la procédure de demande d'avis).

${ }^{143}$ De plus, en pratique, l'avis du CESW remis au gouvernement wallon sur des projets de décret est joint aux documents transmis aux députés wallons dans la continuité du processus législatif. 


\section{ANNEXE : COMPOSITION DES PÔLES}

Les références légales citées ci-dessous se rapportent au décret wallon du 6 novembre 2008 portant rationalisation de la fonction consultative ${ }^{144}$, tel que modifié par le décret wallon du 16 février $2017^{145}$.

\section{Pôle « Politique scientifique» $($ article $2 / 2, \S 2)$}

Ce pôle est composé de 21 membres désignés par le gouvernement wallon selon la répartition suivante :

- 10 représentants des interlocuteurs sociaux (sur proposition du CESW) ;

- 6 membres ${ }^{146}$ issus des universités actives en Wallonie ${ }^{147}$;

- 2 membres ${ }^{148}$ issus d'institutions de l'enseignement supérieur non universitaire actives en Wallonie ${ }^{149}$;

- 2 représentants des centres de recherche (sur proposition de Wal-Tech ${ }^{150}$ );

- 1 représentant des associations environnementales reconnues en vertu du Code de l'environnement (sur proposition d'Inter-Environnement Wallonie - IEW).

En outre, assiste aux réunions du pôle avec voix consultative : l'administrateur général de l'Institut wallon de l'évaluation, de la prospective et de la statistique (IWEPS).

Le pôle élit en son sein un président et un vice-président.

2. Pôle « Mobilité » (article $2 / 3, \S 2)$

Ce pôle est composé de 21 membres désignés par le gouvernement wallon selon la répartition suivante :

- 8 représentants des interlocuteurs sociaux (sur proposition du CESW);

144 Moniteur belge, 18 décembre 2008.

145 Moniteur belge, 5 avril 2017 (et erratum : Moniteur belge, 4 mai 2017).

146 Ils sont proposés par l'Académie de recherche et d'enseignement supérieur (ARES).

147 Il s'agit des universités reconnues à l'article 10 du décret de la Communauté française du 7 novembre 2013 définissant le paysage de l'enseignement supérieur et l'organisation académique des études (Moniteur belge, 18 décembre 2013). Actuellement, il s'agit donc de l'Université catholique de Louvain (UCL), de l'Université de Liège (ULiège), de l'Université de Namur (UNamur) et de l'Université de Mons (UMons).

148 Ils sont proposés par l'ARES.

149 Il s'agit des hautes écoles reconnues à l'article 11 du décret de la Communauté française du 7 novembre 2013 définissant le paysage de l'enseignement supérieur et l'organisation académique des études.

150 Wal-Tech est l'association des centres de recherche agréés par la Région wallonne. 
- 1 représentant de la Direction générale opérationnelle Routes et Bâtiments (DGO1) du SPW ;

- 1 représentant de la Direction générale opérationnelle Mobilité et Voies hydrauliques (DGO2) du SPW ;

- 1 représentant de la Société régionale wallonne du transport (SRWT);

- 1 représentant de la Société wallonne des aéroports (SOWAER);

- 1 représentant de la Société wallonne de financement complémentaire des infrastructures (SOFICO) ;

- 2 représentants des associations environnementales reconnues en vertu du Code de l'environnement ;

- 2 représentants des pouvoirs locaux (sur proposition de l'Union des villes et communes de Wallonie - UVCW) ;

- 1 représentant des intercommunales de développement économique (sur proposition de Wallonie-Développement ${ }^{151}$ );

- 1 représentant des ports autonomes ;

- 2 représentants des usagers (sur proposition des organisations représentatives de ces usagers).

3. Pôle « Environnement» (article 2/4, § 2)

Ce pôle est composé de 17 membres permanents désignés par le gouvernement wallon selon la répartition suivante :

- 8 représentants des interlocuteurs sociaux (sur proposition du CESW) ;

- 4 représentants des associations environnementales reconnues en vertu du Code de l'environnement ;

- 2 représentants des pouvoirs locaux (sur proposition de l'Union des villes et communes de Wallonie - UVCW) ;

- 2 membres ${ }^{152}$ issus des universités actives en Wallonie ${ }^{153}$, dont les compétences doivent couvrir l'un des domaines suivants: écologie, sciences naturelles; agronomie, sylviculture, ressources du sous-sol; économie et droit de l'environnement ; sciences appliquées (pollutions industrielles, gestion des eaux, gestion de la qualité de l'air, gestion des déchets) ; santé publique, toxicologie ;

- 1 représentant des consommateurs (sur proposition des associations représentatives des consommateurs).

\subsection{Section « Eau » (article $2 / 4, \S 3)$}

En cas de dossier relatif à la politique de l'eau, siège au sein du pôle, avec voix délibérative, la section «Eau». Celle-ci est composée de 10 à 11 membres additionnels désignés par le gouvernement wallon selon la répartition suivante :

${ }_{151}^{151}$ Wallonie-Développement est l'association des intercommunales wallonnes de développement économique.

${ }_{153}^{152}$ Ils sont proposés par l'ARES.

153 Cf. supra. 
- 8 membres représentant le secteur de la production et de la distribution d'eau, de l'assainissement et du démergement (sur proposition d'Aquawal ${ }^{154}$ ) ;

- 1 représentant des organisations représentatives des pêcheurs ;

- 1 représentant des contrats de rivières ;

- 1 représentant d'associations d'agriculteurs, d'horticulteurs et d'éleveurs (si le secteur n'est pas représenté par les interlocuteurs sociaux).

3.2. Section « Déchets » (article $2 / 4, \$ 4)$

En cas de dossier relatif à la politique des déchets, siège au sein du pôle, avec voix délibérative, la section «Déchets ». Celle-ci est composée de 9 à 10 membres additionnels désignés par le gouvernement wallon selon la répartition suivante :

- 3 représentants de la Conférence permanente des intercommunales wallonnes de gestion des déchets (COPIDEC) ;

- 2 représentants des associations professionnelles des opérateurs de droit privé du secteur des déchets ;

- 2 représentants des secteurs de la chimie, des cimenteries, de l'électricité, des fabrications métallurgiques, de la construction, de la sidérurgie, de l'industrie de la récupération de l'emballage ou du traitement des déchets (et dont le secteur n'est pas représenté par les interlocuteurs sociaux);

- 1 représentant de l'économie sociale active dans le secteur de l'environnement ;

- 1 représentant d'associations d'agriculteurs, d'horticulteurs et d'éleveurs (si le secteur n'est pas représenté par les interlocuteurs sociaux);

- 1 représentant de l'Institut scientifique de service public (ISSEP).

\subsection{Section « Sols» $($ article $2 / 4, \S 5)$}

En cas de dossier relatif à la politique des sols, siège au sein du pôle, avec voix délibérative, la section "Sols ». Celle-ci est composée de 9 à 10 membres additionnels désignés par le gouvernement wallon selon la répartition suivante :

- 3 représentants du secteur industriel ;

- 2 représentants d'organismes chargés de la production et de la distribution d'eau (sur proposition d'Aquawal) ;

- 1 représentant de l'association professionnelle représentant le secteur de l'assainissement des sols ;

- 1 représentant de l'association professionnelle représentant le secteur des bureaux d'études ;

- 1 représentant de la Société publique d'aide à la qualité de l'environnement (SPAQUE) ;

- 1 représentant de l'Institut scientifique de service public (ISSEP);

- 1 représentant d'associations d'agriculteurs, d'horticulteurs et d'éleveurs (si le secteur n'est pas représenté par les interlocuteurs sociaux).

154 Aquawal est l'union professionnelle des opérateurs publics du cycle de l'eau en Wallonie. 


\section{Pôle « Aménagement du territoire » (article $2 / 5, \S 2{ }^{155}$ )}

Ce pôle est composé, outre du président, de 24 membres désignés par le gouvernement wallon.

La section «Aménagement régional » comporte 12 sièges, répartis comme suit :

- 4 pour les interlocuteurs sociaux (tels que représentés au CESW);

- 1 pour le représentant des pouvoirs locaux;

- 1 pour le représentant des organisations environnementales;

- 2 pour les représentants des intercommunales de développement;

- 1 pour le représentant du secteur carrier;

- 1 pour le représentant des associations d'urbanistes ;

- 1 pour le représentant de la Conférence permanente du développement territorial (CPDT) ;

- 1 pour le représentant du secteur agricole.

La section «Aménagement opérationnel » comporte 12 sièges, répartis comme suit :

- 4 pour les interlocuteurs sociaux (tels que représentés au CESW);

- 1 pour le représentant des pouvoirs locaux;

- 1 pour le représentant des organisations environnementales;

- 2 pour les représentants du secteur du logement;

- 1 pour le représentant de la Fondation rurale de Wallonie (FRW) ;

- 1 pour le représentant du développement urbain ;

- 2 pour les représentants des associations d'architectes.

5. Pôle « Ruralité » (article $2 / 6, \S 2)$

Ce pôle est composé de 16 membres permanents ${ }^{156}$ désignés par le gouvernement wallon selon la répartition suivante :

- 2 représentants des interlocuteurs sociaux (sur proposition du CESW) ;

- 2 représentants des associations environnementales reconnues en vertu du Code de l'environnement ;

- 2 représentants des pouvoirs locaux (sur proposition de l'Union des villes et communes de Wallonie - UVCW) ;

- 2 représentants sur proposition des associations agricoles wallonnes, dont 1 membre siégeant dans la section " Agriculture, agro-alimentaire et alimentation »;

- 2 représentants sur proposition des associations forestières et de la filière bois, dont 1 membre siégeant dans la section «Forêt et filière bois »;

- 2 représentants des associations de propriétaires privés ruraux ;

- 1 représentant des associations de propriétaires publics;

- le président de la section «Chasse » ou son représentant;

${ }_{156}$ La composition de ce pôle est fixée à l'article D.I.5 du Code du développement territorial (CODT).

156 Les membres permanents siègent en présence d'une des sections du pôle. 
- le président de la section «Pêche » ou son représentant;

- le président de la section « Nature » ou son représentant.

En outre, assiste aux réunions du pôle avec voix consultative : 1 représentant de la Direction générale opérationnelle Agriculture, Ressources naturelles et Environnement (DGO3) du SPW.

\subsection{Section « Nature» (article $2 / 6, \S 3)$}

En cas de dossier relatif à la conservation de la nature, siège au sein du pôle, avec voix délibérative, la section « Nature ». Celle-ci est composée de 10 membres additionnels, dont au minimum 1 membre germanophone, qui sont désignés par le gouvernement wallon selon la répartition suivante :

- 6 membres ${ }^{157}$ issus des universités actives en Wallonie ${ }^{158}$, des institutions de l'enseignement supérieur non universitaire actives en Wallonie ${ }^{159}$ ou des centres de recherches agréés actifs en Wallonie ${ }^{160}$, dont les programmes d'études ou de recherches touchent aux disciplines ou aux domaines suivants : le règne végétal; le règne animal ; la connaissance et la gestion du milieu naturel ;

- 4 représentants issus des fédérations, des associations ou des organisations non gouvernementales ayant pour objet la conservation de la nature et la protection de l'environnement, dont les attributions ou les compétences exercées sur l'ensemble du territoire wallon ou sur une partie importante de ce territoire concernent les aspects ou thèmes indicatifs suivants: la sauvegarde de la biodiversité ; la gestion des sites naturels protégés ; l'éducation à la conservation de la nature; le développement des parcs naturels ; la formation des guides nature.

\subsection{Section « Chasse » (article $2 / 6, \S 4)$}

En cas de dossier relatif à la chasse, siège au sein du pôle, avec voix délibérative, la section « Chasse ». Celle-ci est composée de 18 membres additionnels désignés par le gouvernement wallon selon la répartition suivante :

- 16 représentants, dont au minimum 1 membre germanophone, des différentes zones cynégétiques, des différents modes de chasse et des associations ou groupements les plus représentatifs du monde de la chasse ${ }^{161}$;

- 2 représentants ${ }^{162}$ issus des universités actives en Wallonie ${ }^{163}$, des institutions de l'enseignement supérieur non universitaire actives en Wallonie ${ }^{164}$ ou des centres de recherches agréés actifs en Wallonie ${ }^{165}$, dont les programmes d'études ou de recherches touchent aux disciplines ou domaines de la chasse et du gibier.

${ }_{157}$ Ils sont proposés par l'ARES.

158 Cf. supra.

159 Cf. supra.

${ }^{60}$ Il s'agit des centres de recherches agréés tels que définis à l'article 10 , alinéa $1^{\text {er }}$, du décret wallon du 3 juillet 2008 relatif au soutien de la recherche, du développement et de l'innovation en Wallonie, Moniteur belge, 29 juillet 2008.

16. Ces membres sont titulaires d'un permis de chasse délivré en Région wallonne.

162 Ils sont proposés par l'ARES.

163 Cf. supra.

164 Cf. supra.

165 Cf. supra. 


\subsection{Section «Pêche » (article $2 / 6, \S 5)$}

En cas de dossier relatif à la pêche, siège au sein du pôle, avec voix délibérative, la section «Pêche». Celle-ci est composée de 20 membres additionnels désignés par le gouvernement wallon selon la répartition suivante :

- 16 représentants, dont au minimum 1 membre germanophone, des associations de pêcheurs ${ }^{166}$;

- 2 représentants des pisciculteurs;

- 2 représentants ${ }^{167}$ issus des universités actives en Wallonie ${ }^{168}$, des institutions de l'enseignement supérieur non universitaire actives en Wallonie ${ }^{169}$ ou des centres de recherches agréés actifs en Wallonie ${ }^{170}$, dont les programmes d'études ou de recherches touchent aux disciplines ou domaines de la pêche et la biologie des poissons.

\subsection{Section « Forêt et filière bois » (article $2 / 6, \S 6)$}

En cas de dossier relatif à la forêt ou à la filière bois, siège au sein du pôle, avec voix délibérative, la section "Forêt et filière bois ». Celle-ci est composée de 14 membres additionnels, dont au minimum 1 membre germanophone, désignés par le gouvernement wallon selon la répartition suivante :

- 2 représentants des interlocuteurs sociaux (sur proposition du CESW);

- 6 représentants des associations de la filière bois ;

- 2 membres ${ }^{171}$ issus des universités actives en Wallonie ${ }^{172}$ organisant la formation des ingénieurs dans le domaine de la nature et des forêts ;

- 2 représentants des associations relatives à la fonction socio-récréative de la forêt ;

- 2 représentants des associations d'entrepreneurs de travaux forestiers.

5.5. Section «Agriculture, agro-alimentaire et alimentation » (article $2 / 6, \S 6$ )

En cas de dossier relatif à l'agriculture, à l'agro-alimentaire et à l'alimentation, siège au sein du pôle, avec voix délibérative, la section "Agriculture, agro-alimentaire et alimentation». Celle-ci est composée de 20 membres additionnels désignés par le gouvernement wallon selon la répartition suivante :

- 2 représentants des interlocuteurs sociaux (sur proposition du CESW);

- 8 représentants, dont au minimum 1 membre germanophone, sur proposition des associations agricoles wallonnes;

- 6 représentants sur proposition des associations professionnelles du secteur de l'agro-alimentaire et de la distribution ;

- 2 représentants des consommateurs (sur proposition des associations représentatives des consommateurs) ;

${ }_{167}^{166}$ Ces membres sont titulaires d'un permis de pêche délivré en Région wallonne.

167 Ils sont proposés par l'ARES.

168 Cf. supra.

169 Cf. supra.

170 Cf. supra.

${ }_{172}$ Ils sont proposés par l'ARES.

172 Cf. supra. 
- 2 membres ${ }^{173}$ issus des universités actives en Wallonie ${ }^{174}$, des institutions de l'enseignement supérieur non universitaire actives en Wallonie ${ }^{175}$ ou des centres de recherches agréés actifs en Wallonie ${ }^{176}$, dont les programmes d'études ou de recherches touchent aux disciplines ou aux domaines de l'agriculture, l'agroalimentaire et l'alimentation.

\section{Pôle « Énergie » (article $2 / 7, \$ 2{ }^{177}$ )}

Ce pôle est composé de 22 membres désignés par le gouvernement wallon selon la répartition suivante :

- 6 représentants des interlocuteurs sociaux;

- 2 représentants des consommateurs résidentiels ;

- 1 représentant des gros consommateurs;

- 2 représentants des pouvoirs locaux (sur proposition de l'Union des villes et communes de Wallonie - UVCW) ;

- 1 représentant des centres publics d'action sociale (sur proposition de la Fédération des CPAS) ;

- 1 représentant des associations environnementales reconnues en vertu du Code de l'environnement ;

- 1 représentant des associations actives dans le domaine de l'énergie ;

- 4 représentants des producteurs, dont :

- 1 représentant des producteurs centralisés,

- 1 représentant des producteurs d'énergie renouvelable,

- 1 représentant des producteurs d'énergie à partir de cogénération de qualité,

- 1 représentant des auto-producteurs;

- 3 représentants des gestionnaires de réseau de transport local et de distribution ;

- 2 représentants des fournisseurs de gaz et d'électricité.

En outre, assistent aux réunions du pôle avec voix consultative :

- le président ou un directeur de la Commission wallonne pour l'énergie $\left(\right.$ CWAPE $\left.^{178}\right)$;

- 1 représentant de la Direction générale opérationnelle de l'Aménagement du territoire, du Logement, du Patrimoine et de l'Énergie (DGO4) du SPW.

${ }^{173}$ Ils sont proposés par l'ARES.

${ }_{174}$ Cf. supra.

Cf. supra.

176 Cf. supra.

177 La composition de ce pôle est fixée à l'article $51, \$ 1^{\text {er }}$, du décret wallon du 12 avril 2001 relatif à l'organisation du marché régional de l'électricité (Moniteur belge, $1^{\text {er }}$ mai 2001) et des missions visées à l'article 44 du décret wallon du 19 décembre 2002 relatif à l'organisation du marché régional du gaz (Moniteur belge, 11 février 2003).

178 La CWAPE est l'instance régionale de régulation des marchés de l'électricité et du gaz. 
7. Pôle « Logement » (article $\left.2 / 8, \S 2{ }^{179}\right)$

Ce pôle est composé de 32 membres désignés par le gouvernement wallon selon la répartition suivante :

- 8 représentants des interlocuteurs sociaux (sur proposition du CESW) ;

- 8 représentants du secteur résidentiel, dont :

- 1 représentant des locataires,

- 1 représentant des propriétaires,

- 1 représentant des notaires,

- 1 représentant des architectes,

- 2 représentants du monde associatif, dont le Réseau wallon de lutte contre la pauvreté (RWLP),

- 1 représentant des associations actives dans le secteur des aînés,

- 1 représentant des organisations représentatives de l'environnement ;

- 3 représentants des pouvoirs locaux, dont :

- 2 sur proposition de l'Union des villes et communes de Wallonie (UVCW),

- 1 sur proposition de la Fédération des CPAS ;

- 2 représentants d'organismes à finalité sociale ;

- 2 représentants des sociétés de logement de service public;

- 3 membres ${ }^{180}$ issus des universités actives en Wallonie ${ }^{181}$ dont les programmes d'études ou de recherches touchent à la politique du logement ;

- 6 représentants des opérateurs de mise en œuvre du droit au logement créés par le Code wallon du logement et de l'habitat durable (CWLHD), dont :

- 2 représentants de la Société wallonne du logement (SWL),

- 2 représentants de la Société wallonne du crédit social (SWCS),

- 2 représentants du Fonds du logement des familles nombreuses de Wallonie (FLW).

En outre, assiste aux réunions du pôle avec voix consultative : un représentant du Département du Logement de la Direction générale opérationnelle de l'Aménagement du territoire, du Logement, du Patrimoine et de l'Énergie (DGO4) du SPW.

179 La composition de ce pôle est fixée à l'article $200 \mathrm{du}$ Code wallon du logement et de l'habitat durable (CWLHD).

${ }^{180}$ Ils sont proposés par l'ARES.

181 Cf. supra. 


\section{CENTRE DE RECHERCHE ET D'INFORMATION SOCIO-POLITIQUES}

Le CRISP, Centre de recherche et d'information socio-politiques, est un organisme indépendant. Ses travaux s'attachent à montrer les enjeux de la décision politique, à expliquer les mécanismes par lesquels elle s'opère, et à analyser le rôle des acteurs qui y prennent part, que ces acteurs soient politiques, économiques, sociaux, associatifs, etc.

Par ses publications, le CRISP met à la disposition d'un public désireux de comprendre la société belge des informations de haute qualité, dans un souci d'exactitude, de pertinence et de pluralisme. Son objectif est de livrer à ce public les clés d'explication du fonctionnement du système socio-politique belge et de mettre en évidence les structures réelles du pouvoir, en Belgique et dans le cadre de l'Union européenne.

Le Courrier hebdomadaire paraît au rythme de 40 numéros par an, certaines livraisons correspondant à deux numéros. Chaque livraison est une monographie consacrée à l'étude approfondie d'un aspect de la vie politique, économique ou sociale au sens large. La revue du CRISP constitue depuis 1959 une source d'information incontournable sur des sujets variés : partis politiques, organisations représentatives d'intérêts sociaux et groupes de pression divers, évolution et fonctionnement des institutions, négociations communautaires, histoire politique, groupes d'entreprises et structures du tissu économique, conflits sociaux, enseignement, immigration, vie associative et culturelle, questions environnementales, européennes, etc. C'est également dans le Courrier hebdomadaire que sont publiés les résultats des élections commentés par le CRISP.

Les auteurs publiés sont soit des chercheurs du CRISP, formés en diverses disciplines des sciences humaines, soit des spécialistes extérieurs provenant des mondes scientifique, associatif et socio-politique. Dans tous les cas, les textes sont revus avant publication par le rédacteur en chef et par un groupe d'experts sélectionnés en fonction de la problématique abordée, afin de garantir la fiabilité de l'information proposée. Cette fiabilité, ainsi que la rigoureuse objectivité du Courrier hebdomadaire, constituent les atouts principaux d'une revue dont la qualité est établie et reconnue depuis près de 60 ans.

Fondateur : Jules Gérard-Libois

Président : Vincent de Coorebyter

Équipe de recherche :

Pierre Blaise (secrétaire général), Fabienne Collard, Vaïa Demertzis, Jean Faniel (directeur général), Christophe Goethals, Cédric Istasse, John Pitseys, David Van Den Abbeel (coordinateur du secteur Économie), Marcus Wunderle

Conseil d'administration :

Louise-Marie Bataille, Jacques Brassinne de La Buissière (vice-président honoraire), Vincent de Coorebyter (président), Francis Delpérée, Hugues Dumont, Éric Geerkens, Nadine Gouzée, Serge Govaert, Laura Iker, Patrick Lefevre, Michel Molitor (vice-président), Solveig Pahud, Pierre Reman (administrateur délégué), Robert Tollet (vice-président), Els Witte, Paul Wynants 


\section{Derniers numéros du Courrier hebdomadaire parus}

2363 Les mutations de la coopération belge au développement au prisme des ONG

Justine Contor

2361-2362 Le dossier Arco Serge Govaert

2359-2360 Évolution de la pratique de la Commission bancaire (1935-1975) Thibaud Giddey

2357-2358 Formation et spécificités historiques de la Commission bancaire (1935-1975) Thibaud Giddey

2355-2356 La Ligue des familles (1950-1975) Élodie Tallier

2353-2354 Le Processus de Kimberley et la lutte contre le commerce des "diamants de sang" Élise Rousseau

2352 Le projet de Centre de formation pour sportifs de haut niveau (CFSHN) Jérôme Defosse

2350-2351 L'autonomie constitutive des entités fédérées Quentin Peiffer

2348-2349 La régulation publique de la biomédecine. Procréation médicalement assistée, recherche sur embryons, gestation pour autrui Nathalie Schiffino

2346-2347 Distribution et redistribution des revenus : évolution des inégalités en Belgique Christian Valenduc

2344-2345 Le G1000 : une expérience citoyenne de démocratie délibérative M. Reuchamps, D. Caluwaerts, J. Dodeigne, V. Jacquet, J. Moskovic et S. Devillers

$2343 \quad$ Le profil des parlementaires néerlandophones en 2015 Jef Smulders

2341-2342 Grèves et conflictualité sociale en 2016 Iannis Gracos

La collection intégrale du Courrier hebdomadaire est accessible sur www.cairn.info.

L'accès est gratuit pour les numéros parus avant 2016.

Découvrez notre catalogue complet incluant nos autres publications sur www.crisp.be.

Pour être informé de nos publications dès leur parution, inscrivez-vous en ligne à notre lettre d'information électronique. 